\title{
The Importance Of Neuronal Plasticity In The Prognosis Of Cases Of Cerebral Ischemia: A Systematic Review

João Vitor Cândido Pimental ${ }^{1}$, Virna Costa dos Santos ${ }^{1}$, Caio Anderson Farias Gonçalves ${ }^{1}$, Antonio Gilvan Teixeira Júnior1, Daniel Libório Sampaio1, Carlos Kennedy Tavares Lima², Florido Sampaio das Neves Peixoto², Jorge André Cartaxo Peixoto², João Marcos Ferreira de Lima Silva ${ }^{3}$, Francisco Antônio Vieira dos Santos ${ }^{3}$, Cícera Janielly de Matos Cassiano ${ }^{3}$, Patrícia Gonçalves Pinheiro ${ }^{3}$, Alberto Olavo Advincula Reis ${ }^{4}$, Carlos Augusto Carvalho de Vasconcelos ${ }^{5}$, Nádia Nara Rolim Lima ${ }^{6}$, Modesto Leite Rolim Neto 1,2,3

\section{Abstract}

Background: Neuronal plasticity is the capacity that the neurons have to make new connections and enable new ways of transmitting information. Under this context, new methodologies are being addressed in order to measure how important this neuronal capacity is in the process of full recovery of learning in subjects who suffered damage from cerebral ischemia.

Methods: A systematic review was performed on the online databases: Medical Literature Analysis and Retrieval System Online (MEDLINE) and Scopus, between 1998 and 2014. The MeSH (Medical Subject Headings) descriptors used in this review were: "neuronal plasticity", "brain ischemia" and "learning". We found 164 articles that, when screened, resulted in 46 articles that met the criteria of evidence and were included in this review.

Results: There are several ways available in the literature to increase neuronal plasticity to keep the learning process after bad conformations resulting from cerebral ischemia. We highlighted the most elucidated: those promoted by SMe1EC2 antioxidant, which brings therapeutic benefits when neuronal plasticity is impaired; and Atorvastatin, a statin which facilitates recovery of spatial learning. It is further observed that the body has a number of intrinsic devices,
1 Faculty of Medicine. Federal University of Cariri, UFCA, Barbalha, Ceara, Brazil.

2 Faculty of Medicine, Postgraduate Program in Health Sciences, FMABC, Santo Andre, Sao Paulo, Brazil.

3 Faculty of Medicine, Estacio, Juazeiro do Norte, Ceara, Brazil.

4 Postgraduate Program in Public Health, University of São Paulo, USP, São Paulo, Brazil.

5 Department of Nutrition, Center of Health Sciences, Federal University of Pernambuco, UFPE, Recife, Pernambuco, Brazil.

6 Postgraduate Program in Neuropsychiatry, Federal University of Pernambuco, UFPE, Recife, Pernambuco, Brazil.

Contact information:

Modesto Leite Rolim Neto.

Đ modestorolim@yahoo.com.br 
such as the endogenous compensatory mechanisms that contribute to the development of neuronal plasticity when there is brain damage caused by ischemia.

Conclusion: The improvement of neuronal plasticity appears in several studies mapped as a new and still little explored possibility of treatment of damages caused by brain processes of oxygen deprivation. Multiple devices, endogenous and exogenous, that promote an increase in neuronal plasticity, are being elucidated in an attempt to promote the full recovery of the learning process, decreased by brain damage from ischemic processes. Thus, it is pointed the necessity of scientific studies that allows to define and maximize the potentials of the neuronal plasticity.

\section{Keywords}

Cerebral Ischemia, Neuroplasticity, Neuronal Recovery, Learning Enhancement

\section{Introduction}

Chronic cerebral ischemia is the common pathological process of the development of various diseases, such as Vascular Dementia, Alzheimer's disease and Binswanger's disease, and eventually cause cognitive impairment $[1,33]$. It was also noticed that the cerebral ischemia resulting from an inadequate supply of blood and oxygen to the brain due to cerebrovascular disease, cardiac arrest, or traumatic brain injury is often accompanied by neuropsychiatric symptoms $[2,3,4,92]$. In an attempt to mitigate these negative consequences, the body develops some defenses, such as motor cortex neuronal changes within motor cortex that include up regulation of trophic factors, like BDNF, attacking increase in protein synthesis, synaptogenesis, and map reorganization $[5,120]$, because recovery might be enhanced not only by dampening inflammation, but also by increasing synaptic and structural plasticity [6].

Thus, it was realized that studies have their focus on endogenous conformations or procedures/exogenous substances that can mitigate the damage.
As examples of these, there Bone Marrow Stromal Cells (BMSC), which, when transplanted, were demonstrated to improve from the function of spatial learning and memory of rats with chronic cerebral ischemia [7, 33] and Netrin-1, a laminin-related protein, which ameliorates spatial memory impairment and improves synaptic dysfunction as observed by the recovery of population spike component of basal evoked potential and LTP in rats with global ischemia [8]. As example of these, there are atorvastatin (ATV), a statin that protects against ischemiainduced misbalance by blocking NMDA receptor downregulation GluN1, decreasing GluN2B upregulation, and restoring the association of GluN1 / PSD5 in clusters [9], and ceftriaxone, a $\beta$-lactam antibiotic that, when administered before the onset of the cerebral artery occlusion, was found to reduce infarct size [10].

Knowing that neuronal plasticity plays an important role in trying to recover the normal function of neurons after cerebral ischemia processes, this study was based on the following question: neuro- 
nal plasticity, after the occurrence of cerebral ischemia, may reintroduce the learning process? And, if so, how is this reintroduction? Thus, this research was conducted through a systematic review aims to update the knowledge about the ability of neuronal plasticity in the reintroduction of learning after brain ischemia, identifying which are the endogenous and exogenous substances and conformations involved in such a process and, finally, identifying therapeutic approaches to guide the development of new research in the area.

\section{Methods}

With emphasis on prognosis in cases of cerebral ischemia, a qualitative systematic review of articles about the importance of neuronal plasticity was carried out on a basis of preselected data. A search of the literature was performed from the online databases MEDLINE and SCOPUS, between June 5 and July 18, 2014, from 1995 to 2014. The reason to establish the time limit between 1995 and 2014 was because there were more published articles in this period. However, it was noted the high visibility of this thematic field due to the higher proportion of current articles compared to the old. The search was focused on the MEDLINE and SCOPUS data from the following terms: 1. "Neuronal plasticity" (Medical Subject Headings) [MeSH term]; 2. "Brain ischemia" (Medical Subject Headings) [MeSH term]; 3. "Learning" (Medical Subject Headings) [MeSH term].

The choice of these three MeSH terms was made from a careful concatenation, which sought to define our central question of the article based on demand descriptors. Therefore, research strategies and articles were evaluated in different situations and with great scientific rigor to ensure proper sampling.

The analysis of the articles followed predefined eligibility criteria. We adopt the following inclusion criteria: (1) Original articles with full text online ac- cess; (2) studies that contained in the title at least a combination of the descriptors; (3) observational, experimental or quasi-experimental studies; (4) Writings in English only; and (5) studies which focus on the importance of neuronal plasticity in the recovery of learning process after cerebral ischemia. Exclusion criteria were: (1) other projects, such as case reports, case series, literature review and comments; (2) The non-original studies, including editorials, comments, prefaces, brief comments and letters to the editor; (3) Items pictured; (4) productions that did not address the neuronal plasticity and cerebral ischemia or the learning process; and (5) the articles in which the objective of the study did not matched the theme pursued by the systematic review in question.

Then each item was read in its entirety and compositional elements extracted from them came in an array that included authors, publication year, sample description of the study and the main findings. Some studies dealing with pre-ischemic neuroprotection were also availed by the understanding that they have an intimate relationship with the postischemic neuronal plasticity.

\section{Results}

Initially the search using the strategies and criteria mentioned resulted in 98 articles in the PubMed and 66 articles in SCOPUS. 45 titles were excluded because they belonged to both databases. After an analysis of the title, abstract and body of the remaining references based on inclusion criteria of the study, the eligibility of those articles able to appear in the final text of the review, 73 articles were excluded and 46 articles were retrieved and included in the present study and in the final tables (Figure 1).

Table 1 shows an overview of selected articles as well as their main findings, methods of control and data publication 
Figure 1: Flow diagram summarizing the procedure for selection of studies for review.

\section{SCOPUS}

1) "Brain ischemia" (MeSH term)

2) "Learning" (MeSH term)

3) "Neuronal plasticity" (MeSH term)

Index: Article title, Abstract, Keywords.

Period: 01.01.1995 to 20.06.2014

\section{PUBMED}

1) "Brain ischemia" (MeSH term)

2) "Learning" (MeSH term)

3) "Neuronal plasticity" (MeSH term)

Filters: Journal Article, Full text, English. Period: 01.01.1995 to 20.06.2014

\section{Inclusion criteria}

1. Original articles with access to full text via access

to SCOPUS database or PubMed;

2. Articles in the title that had at least one combination of the terms described in the search strategy;

3. Observational, experimental or quasi-experimental studies;

4. Articles written in English;

5. Studies that deal with the importance of neuronal plasticity for recovery of the learning process after cerebral ischemia

\section{References to full text analyzed for eligibility; $(n=119)$}

Studies included in this review $(n=46)$
73 references excluded after examined the summary and the text, if available:

1. Not about neuronal plasticity, or cerebral ischemia or learning process $(n=21)$;

2. Case Report $(n=1)$;

3. Summary or Full text not available in SCOPUS or PubMed ( $n=14)$;

4. Review of Literature $(n=33)$;

5. Retracted article $(n=1)$;

6. Letter to editor $(n=3)$. 
Table 1. Overview of selected articles.

\begin{tabular}{|c|c|c|}
\hline Authors & Journal & Sample \\
\hline $\begin{array}{l}\text { Gutierrez- } \\
\text { Vargas et } \\
\text { al. [9] } 2014\end{array}$ & $\begin{array}{l}\text { Journal of } \\
\text { Neuroscience } \\
\text { Research }\end{array}$ & $\begin{array}{l}\text { Male Wistar albino rats from our in-house, } \\
\text { pathogen-free colony of the species at the } \\
\text { vivarium at SIU, University of Antioquia, were } \\
\text { kept on a } 12 \text { hr dark-light cycle and received } \\
\text { food and water ad libitum. Three-month-old } \\
\text { rats weighting } 250-310 \mathrm{~g} \text { were used. Fifteen } \\
\text { rats per group were used for neurological } \\
\text { scoring. Of these, nine rats in each group were } \\
\text { subjected to spatial-learning and memory } \\
\text { evaluation. Four or five rats per experimental } \\
\text { group were dedicated for histological and } \\
\text { biochemical assessments. }\end{array}$ \\
\hline $\begin{array}{l}\text { Tang Q } \\
\text { et al. [60] } \\
2013\end{array}$ & $\begin{array}{c}\text { Behavioural Brain } \\
\text { Research }\end{array}$ & $\begin{array}{l}\text { A total of } 114 \text { adult male Sprague Dawley } \\
\text { rats weighing } 200 \text { to } 250 \mathrm{~g} \text { were used In the } \\
\text { study. All animals were kept on a } 12 \mathrm{~h} \text { light/ } \\
\text { dark cycle at } 23 \pm 2^{\circ} \mathrm{C} \text { room temperature. Rats } \\
\text { with a neurological deficit score of } 2 \text { and } 3 \text {, as } \\
\text { evaluated at } 2 \mathrm{~h} \text { after recirculation, were use } \\
\text { in this study. Littermate rats were randomly } \\
\text { assigned to one of four groups: normal control } \\
\text { rats that did not receive middle cerebral } \\
\text { artery occlusion (MCAO) (NC, } \mathrm{n}=18) \text {, rats } \\
\text { that received only MCAO (MCAO, } n=18 \text { ), rats } \\
\text { that additionally experienced environmental } \\
\text { modification (EM, } n=18) \text {, and rats that } \\
\text { additionally received willed-movement therapy } \\
\text { (WM, } n=18 \text { ). }\end{array}$ \\
\hline
\end{tabular}

Li J et al Biomedical Male mongolian gerbils, aged 13 to 16 weeks

[92] 2013 Research (Japan) with a body weight of 60 to $80 \mathrm{~g}$, were housed one to a cage in the Animal Center of our university on a 12-h/12-h light/dark cycle at a room temperature of about $23^{\circ} \mathrm{C}$ with free access to rodent food.

Undén et al. [102] 2013

Kim, S.Y et al. [10] 2013
BMC

Neuroscience

Restorative Neurology and Neuroscience (Møllegaard's Breeding Center, Copenhagen, access to tap water.

Twenty-three male 4 month-old Long-Evans Harlan Laboratories three months before the

\section{Main findings}

Our findings suggest that acute ATV administration after cerebral ischemia protects against morphological and functional brain damage and facilitates long-term spatial-learning and memory recovery by a GluN2B NMDA receptor subunit-dependent mechanism. ATV treatment restored neurological scores faster than placebo, prevented the appearance of pyknotic neurons, and restored MAP2 and NeuN staining to control values in the somatosensory cerebral cortex and the hippocampus.

Our previous [4] and present data indicated That WM training for rats could improve neurobehavioral Performance relative to EM and MCAO rats. The improvement of the motor performance might Be the result of a change in basal synaptic transmission Following the WM training

These results suggest that the recovery of spatial learning in group T-20 might not be due to functional recovery or cellular regeneration of hippocampal CA1 neurons themselves from the severe ischemic damage, but rather to functional compensation for the ischemiainduced damage to hippocampal CA1 neurons by neural networks of learning in the extraCA1 regions.

We show that EPO has no influence on neuronal survival and delayed neuronal cell death in the CA1 region in the hippocampus, Denmark), which were fasted overnight with free cortex and striatum of rats subjected to hooded rats were used. Rats were received from onset of experimental procedures, and made tame by handling to minimize stress during training. Animals were housed in pairs on a 12: 12 hour light:dark cycle, receiving water ad libitum. ischemia but treatment significantly preserved memory function.

The present findings of detrimental effects of ceftriaxone on motor behavioral outcome indicate the need for a more thorough characterization of dose-response and temporal profiles of post-ischemic treatment effects on behavioral function, and for careful consideration of the timing of its administration post-stroke. 


\begin{abstract}
Bayat et al. Brain Research Sixty male Wistar rats (Pasteur institute,
[8] 2012
\end{abstract}

Zhang et

al. [33]

2012

Life Science Journal

Pagnussat

et al. [120]

2012

Adelson et al. [6] 2012

Costa C et al. [58] 2011
Brain Research

Forty three male Wistar rats from a local breeding colony (ICBS, Universidade Federal do Rio Grande do Sul, Brazil) weighing approximately $300 \mathrm{~g}$ at the time of surgery were housed in standard plexiglass boxes, under 12:12 $\mathrm{h}$ light/dark cycle, in a temperature-controlled environment (2071 1 C), with food and water available ad libitum, except during behavioral training and testing periods.

Neuron Report

$\mathrm{KbDb} \mathrm{KO}$ mice, offspring of breeding pairs on a C57BL/6 background, were generously provided by H. Ploegh. C57BL/6 (i.e., KbDb WT) controls were purchased (Charles River). PirB KO and PirB WT controls were previously generated in C.J.S.'s laboratory. Mice were maintained in a pathogenfree environment

Neurobiology of Hippocampal slices (thickness, $400 \mu \mathrm{m}$ ) were Disease cut from 1 to 2-month-old male Wistar rats $(n=38)$ (Harlan, Italy) using a vibratome. Preparation and maintenance of hippocampal slices have been described previously. A single slice was transferred to a recording chamber and submerged in a continuously flowing Krebs' solution $\left(34{ }^{\circ} \mathrm{C} ; 2.5-3 \mathrm{ml} / \mathrm{min}\right.$ ) bubbled with a $95 \%$ O $2-5 \%$ CO 2 gas mixture. The composition of the solution was as follows (in $\mathrm{mol} / \mathrm{L}): 126 \mathrm{NaCl}, 2.5 \mathrm{KCl}, 1.2 \mathrm{MgCl} 2,1.2 \mathrm{NaH} 2$ $\mathrm{PO} 4,2.4 \mathrm{CaCl} 2,10$ glucose and $25 \mathrm{NaHCO}$.
The major findings of the present study showed that the intra hippocampal injection of netrin-1 dose-dependently and significantly ameliorated memory impairment and improved synaptic dysfunction as observed by recovery of population spike component of basal evoked potential and LTP in rats with global ischemia.

The mechanisms of spatial learning and memory improvement caused by BMSCs transplantation may be correlated with downregulation of P75NTR and up-regulation of BDNF which thereby mediated synaptic activity, promoted dendritic and axonal growth, improved self-repair of the nervous system

Our results support that skilled motor activity can induce brain plasticity after brain ischemia despite of no functional improvement in this experimental model of focal ischemia.

Motor performance in $\mathrm{KO}$ mice recovered to a greater degree than in WT, and infarct area was smaller in $\mathrm{KO}$ but only after 7 days and not $24 \mathrm{hr}$ post-MCAO. This delay is consistent with the idea that mechanisms of synaptic plasticity and functional recovery take time and may be more fully engaged in $\mathrm{KO}$ mice.

We found that NO/cGMP/PKG pathway exerts a critical role in the induction the hippocampal iLTP and ZNS, at a non- anticonvulsant dose, reduces this pathological plasticity by modulating this biochemical pathway.
Cao et al.

[154] 2011
Chinese Journal of Physiology
Adult male Wistar rats. Rats were randomly divided into 3 groups for treatment: sham operation (S, $n=8), I / R(I / R, n=40)$, and I/R + UTI treatment $(U, n=40)$. The last 2 groups were divided into 5 sub-groups (8 rats each) for different I/R times (12, 24, 48, 72 and 168 $\mathrm{h}$ after reperfusion).
We found that UTI could improve spatial reference learning and memory in rats with I/R by down regulating S100 $\beta$-positive cells and preventing the loss of neural cells 
List J et al. Cerebral Cortex Twelve patients with CADASIL (aged 48.3 \pm 8.3 [40] 2011

Li et al.

[88] 2011

\section{Neurochemical} Research

Zhu $\mathrm{H}$ et al. [144] 2011 years, range 36-67 years, 8 females) from 8 different families and 12 healthy volunteers (HV) $(49.9 \pm 8.3$ years, range $39-67$ years, 8 females) were included in the present study.

Spaccapelo

$\mathrm{L}$ et al.

[170] 2011 of Pharmacology

Male Mongolian gerbils (Charles River Breeding Laboratories, Calco, Italy) weighing 70-80 g were used. The animals were acclimatized to our housing conditions for at least 1 week before use, and were kept in air-conditioned colony rooms (temperature $21 \pm 1{ }^{\circ} \mathrm{C}$, humidity $60 \%$ ) on a natural light/dark cycle, with food in pellets and tap water available ad libitum.

Male Wistar rats. The rats were randomly divided into four groups $(n=26)$, which were sham group ( $\mathrm{n}=6$, normal saline $5.6 \mathrm{mg} / \mathrm{kg} /$ day, i.p.), NaHS group ( $n=6$, NaHS 5.6 mg/kg/day, i.p.), 2VO group ( $n=6$, normal saline $5.6 \mathrm{mg} / \mathrm{kg} /$ day, i.p.) and 2VO-NaHS group ( $n=8, \mathrm{NaHS} 5.6 \mathrm{mg} / \mathrm{kg}$ / day, i.p. post-2VO). Rats were reared for 3 weeks

\section{Neuroscience Letters}

Sixty-four male Wistar rats weighing 180-200 g Rats were housed at $25+1^{\circ} \mathrm{C}$ with a 12-h light/ dark cycle with free access to food and water.
The present findings suggest that in middleaged individuals, the brain uses endogenous compensatory mechanisms, as indicated by increased rapid-onset cortical plasticity, to successfully counteract damage.

The present data give direct evidence for the first time of the neuroprotective effect of melanocortin MC 4 receptor agonists.

We demonstrated the $\mathrm{H} 2 \mathrm{~S}$ content in hippocampus could be increased by treating with a certain concentration of exogenous H 2 S. H 2 S could improve impairment of learning and memory in brain-ischemic rats. The underlying mechanism was associated with improvement of synaptic plasticity

Our current study demonstrated that EE reversed spatial cognitive impairment and LTP deficits induced by $\mathrm{CCH}$ and enhanced expression of $p C R E B$, synaptophysin, and MAP2. Our study elucidated possible underlying mechanisms of cognitive impairment and improvement after $\mathrm{CCH}$ or exposure to an EE. Thus, exposure to an EE may be a promising therapy for reversing cognitive impairment after $\mathrm{CCH}$.

PROG stimulated the expression of GAP-43, blocked the down regulation of SYP and improved post ischemic synaptogenesis in the CA1 region of the hippocampus. 


\begin{tabular}{c|c} 
Gáspárová & Interdisciplinary \\
et al. [79] & Toxicology \\
2011 & \\
\hline
\end{tabular}

Male Wistar rats, 2 months old, weight $221 \pm$ $11 \mathrm{~g}, \mathrm{n}=40$, from the breeding station Dobrá Voda (Slovak Republic, reg. No. SK CH 4004) were used. The rats had free access to water and food pellets and were kept on 12/12 h light/dark cycle. Animals were acclimated one week prior to the experiments.

Li S. et al.

[57] 2010

\section{Neuroscience}

Twenty-six adult male Sprague-Dawley rats weighing 200-250 g were used to carry out the experiments (Experimental Animal Center, Tongji Medical College, Huazhong University of Science and Technology). They were housed with five per cage in a temperature and humiditycontrolled room (temperature: $1{ }^{\circ} \mathrm{C}$, humidity: $60 \%$ ) with free access to food and water. The rats were kept in a 12-h light and dark cycle. The rats were adapted to housing conditions for at least 7 days before experiments. All of the rats were randomly divided into groups of shamoperated and ischemia

GutiérrezVargas, J et al. [74] 2010

Samson, M.L. et al. [103] 2010

\section{Journal of}

Pharmacology and Experimental

Therapeutics
Wistar albino male rats from the house colony of SPF (Species Pathogen Free) vivarium of SIU (Sede de Investigacio' n Universitaria), at the University of Antioquia, Medellín-Colombia, were kept in a 12:12 h dark:light cycle and received food and water ad libitum. Threemonth-old, adult, male Wistar rats weighting 300-350 g were used

The animal holding rooms were on a 12-h dark/ light cycle, and water and food were provided ad libitum. Male Sprague- Dawley rats 250 to $330 \mathrm{~g}$ obtained from Charles River Canada (Montreal, QC, Canada) were used for experimentation
The LTP-protective effect of SMe1EC2 found in the rat hippocampus exposed to model ischemia may prove beneficial in therapeutic application when neuronal plasticity is injured in some conditions inclu ding ischemia, trauma and aging in man. The mechanism of pyridoindole antioxidant effect in ischemic conditions may differ from the mechanism of its effect in control "normoxic" conditions.

Our report would be the first to describe that the down regulation of HCN1 mRNA in the condition of chronic incomplete global cerebral ischemia induced by bilateral carotid artery ligation. The phenomenon opened new insights for further investigation of the physiological and pathological significances of HCN1 in chronic incomplete global cerebral ischemia

Rac1 is a molecular pivot and convergent target of neuronal survival and plasticity pathways, and its feedback plays a crucial role depending on the specific tisular context and the time period after the cerebral damage to achieve structural and functional recovery

Taken together, these findings suggest that darbepoetin alfa reverses pre-existing spatial working memory deficits resulting from transient global ischemia by increasing the activity of nitric-oxide synthase, an enzyme implicated in synaptic plasticity.

TRPM7 suppression in hippocampal CA1 neurons in vivo is well tolerated, imparts resilience to ischemic damage, and preserves neuronal function and performance for hippocampus-dependent learning tasks after ischemic brain injury 


\begin{abstract}
Yao $Y$ et
al. [80]

2009

Phytotherapy

Reserach

Male Wistar rats ( 6 weeks, $250 \pm 10 \mathrm{~g}$ ) were obtained from the Chinese Academy of Medical Sciences and were randomly divided into three groups, i.e. vehicle group, sham-operated group and quercetin-treated group. Rats in the vehicle and quercetin-treated groups were subjected to permanent bilateral occlusion of their carotid arteries to induce chronic cerebral ischemia and model the effects of VD. In the sham-operation group, the carotid arteries were exposed but not occluded.
\end{abstract}

Giuliani D et al. [65]

Brain, Behavior, and Immunity

2009

Ploughman et al. [28]

2009

Askim et

Neurore-

al. [121]

2009

habilitation and

Neural Repair
We used male 8-9 week-old Mongolian gerbils (Charles River Breeding Laboratories) weighing 70-80 g (No. 116). They were kept in airconditioned colony rooms (temperature $21 \pm 1$ C, humidity $60 \%$ ) on a natural light/dark cycle, with food in pellets and tap water available ad libitum.

\section{Stroke}

Thirty-two male Sprague-Dawley rats (Charles River Laboratories, Montreal, Canada) weighing 250 to 275 grams at the time of surgery were used in this study. Animals were housed in pairs in Plexiglas cages on a 12-hour reverse light/ dark cycle with water and food ad libitum. All procedures were performed during the animals' dark phase.

Patients admitted to the Stroke Unit, St Olavs Hospital, Trondheim, Norway, were screened on the following criteria: age 50 to 75 years, righthandedness, first-ever acute stroke diagnosis, 23 modified Rankin Scale (mRS) score of less than 3 before admission, paresis but no paralysis of the hand or arm item on the Scandinavian Stroke Scale (SSS), 24 Mini-Mental State Examination score exceeding 20, no language impairment, no intra cerebral hemorrhage on computed tomography, no previous neurological or psychiatric disease, living within 60-minute driving distance from the hospital, no MR imaging contraindications, and first fMR imaging within 4 to 7 days after stroke onset.
Adult male Sprague-Dawley rats weighing 200-250 g were used (Experimental Animal Center, Tongji Medical College, Huazhong University of Science and Technology). They were housed 5 per cage in a temperature and humidity-controlled room (temperature: $22 \pm$ 1 C, humidity: $60 \%$ ) with free access to food and water. The rats were kept on a 12-h light/ dark cycle. The rats were acclimatized to housing conditions for at least $4 \mathrm{~d}$ before being used.
In summary, this work showed that quercetin improved the performance of learning and memory of chronic cerebral ischemic rats, reversed the LTP deficit induced by ischemia and inhibited voltage-dependent sodium channels.

Here we show, for the first time, that shortterm treatment of ischemic stroke with nanomolar amounts of the melanocortin NDPa-MSH (agonist at MC 1, MC 3, MC 4 and MC 5 receptors produces long-lasting functional recovery associated with overexpression of the activity-dependent gene Zif268 in the hippocampus.

BDNF is crucial for mediating the motor relearning that takes place as a result of post stroke rehabilitation. Strategies that increase BDNF broadly within the nervous system, such as exercise or BDNF infusion, may enhance neuroplasticity processes in multiple neuronal systems involved in motor relearning during stroke rehabilitation.

The main results showed that successful functional recovery was associated with similar activation patterns in acute and chronic phases, despite significant differences in hand function.

Our findings suggest that chronic hypoperfusion decreases the contents of excitatory and inhibitory amino acids in rat brain and up-regulates the apoptosis-related protein: P53 and BAX. Piracetam inhibited the decrease amino acid content induced by chronic hypoperfusion, ameliorated the dysfunction of learning and memory in HP rats, down-regulated P53 and BAX protein, facilitated the synaptic plasticity, and may be helpful in the treatment of vascular dementia. 


\begin{tabular}{c|c|c|c}
$\begin{array}{c}\text { Maldonado } \\
\text { et al. [112] } \\
2008\end{array}$ & $\begin{array}{c}\text { Neurore- } \\
\text { habilitation and } \\
\text { Neural Repair }\end{array}$ & $\begin{array}{l}\text { Twenty-eight 4-month-old and twelve 1- to 1.6- } \\
\text { year- old female Long-Evans hooded rats that } \\
\text { were bred at the University of Texas at Austin } \\
\text { were pair housed and kept on a } 12 / 12 \mathrm{~h} \text { light/ } \\
\text { dark cycle with water access ad libitum. Animals } \\
\text { were frequently handled } 2 \text { to } 3 \text { weeks prior to } \\
\text { the experiment, and all behavioral procedures } \\
\text { were carried out in the same room in which the } \\
\text { animals were housed. }\end{array}$
\end{tabular}

R.P. Allred, T.A. Jones [44] 2008

Experimental Neurology

Well-handled rats were pair housed with standardized housing supplementation (a PVC pipe piece and small wooden objects) on a 12:12 light/dark cycle. Animals were maintained on scheduled feeding (15-17 g/day) to motivate reaching performance.
He Z et al. European Journal Adult male Sprague-Dawley rats weighing

[81] 2008 of Pharmacology 200-250 g were used (Experimental Animal Center, Tongji Medical College, Huazhong University of Science and Technology). They were housed with 5 per cage in a temperature and humidity-controlled room (temperature: $22 \pm 1{ }^{\circ} \mathrm{C}$, humidity: $60 \%$ ) with free access to food and water. The rats were kept on a 12-h light (07:00-19:00) and dark (19:00-7:00) cycle. The rats were adapted to housing conditions for at least 7 days before experiments. All rats were randomly divided into groups of sham-operated, ischemia and ischemia treated with DDPH.

\begin{tabular}{c|c}
$\begin{array}{c}\text { Huang et } \\
\text { al. [73] }\end{array}$ & Cellular and \\
2008 & Molecular \\
\hline
\end{tabular}

Adult male Sprague-Dawley rats weighing 200-250 g were used (Experimental Animal Center, Tongji Medical College, Huazhong University of Science and Technology). They were housed five per cage in a temperature and humidity-controlled room (temperature: $22 \pm$ 18C, humidity: 60\%) with free F33access to food and water. The rats were kept on a 12-h light/ dark cycle and adapted to these conditions for at least 7 days before experiments. All rats were randomly divided into groups of sham, ischemia and ischemia treated with hydroxyfasudil (1 mg/ $\mathrm{kg}$ and $10 \mathrm{mg} / \mathrm{kg}$ ).
We did find a significant effect of rehabilitative training alone for spinophilin, a dendritic spine protein in the perilesion motor cortex, which may indicate that tray reaching produced synaptogenesis in this region

The present results indicate that experiences with the less-affected forelimb can disrupt neuronal activity in the infarcted hemisphere in a manner linked to greater injury-induced impairments. Additional research is needed to address the timing and persistence of intact forelimb training effects, the causality of its relationship with peri-infarct neural activity, its molecular mechanisms, and the involvement of interhemispheric communication and corticospinal tract in these effects

Administration of DDPH daily for 30 days abolished almost total inhibition of long-term potentiation in rats with chronic cerebral ischemia. These data suggested that DDPH could facilitate the synaptic transmission in hippocampus. These electrophysiology data also support our other results from cognitive studies and from morphology examinations that DDPH could ameliorate the learning and memory impairment and reduce neuronal injury in those chronic ischemic rats.

In conclusion, our results demonstrated that activation of the Rho/Rho-kinase pathway is related to the neuronal damage and the pathogenesis of the spatial learning and memory impairment in BCAL rats. The relative long-term hydroxyfasudil treatment improved spatial learning and memory performance, increased the induction rate and amplitude of LTP and attenuated neuronal damage in this model. The neuroprotective effects of Rho-kinase inhibition by hydroxyfasudil could be attributed to at least two aspects: (1) up regulation of NR2B mRNA and protein expression; (2) reduction in oxidative stress. 
Clarke, J. European Journal The experiments used adult male hAPP695 Tg et al. [109] of Neuroscience 2007

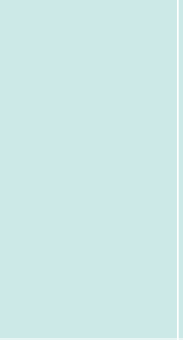

$\mathrm{Hsu}, \mathrm{J.E}$

et al. [52]

2006

Ruan Y.-W.

et al. [14]

2006

\section{Experimental Neurology} rats (APP; $n 1 / 422$ ) and their non-transgenic littermates (NT; n 1/4 19), weighing 375-425 $\mathrm{g}$ at the time of surgery. A separate group of intact adult rats ( $n$ 1/4 6 APP, 5 NT) were used for biochemical analyses. Animals were individually housed in a temperature-controlled environment $(20 \pm 1 C)$, with lights on 07.00-19.00 h. Food and water were available ad libitum, except during periods of food restriction for behavioral testing.
Thirty-three male Long-Evans hooded rats (purchased or bred from Charles-River Laboratories) that were 3 to 4 months of age at the time of surgery were used. Animals were handled briefly everyday for a month before the onset of the experiment. The rats were housed in pairs in transparent cages and received water ad libitum.

Neuroscience

Male adult Wistar rats (200-300 g, Charles River, Wilmington, MA, USA) were used in the present study

\begin{tabular}{c|c}
$\begin{array}{c}\text { Ai and } \\
\text { Baker [48] } \\
2006\end{array}$ & $\begin{array}{c}\text { Experimental } \\
\text { Brain Research }\end{array}$ \\
\hline
\end{tabular}

Animals were deeply anesthetized with 2.0-

$2.5 \%$ halothane and decapitated. The forebrain from rats was immediately removed (within $1 \mathrm{~min}$ ) and maintained in an ice-cold artificial cerebrospinal fluid (ACSF) aerated with 95\% O 2-5\% CO 2 . Transverse slices of the forebrain containing the hippocampus $(400 \mathrm{~lm})$ were prepared from Sprague-Dawley rats 50-60 days old using a Vibratome

\begin{tabular}{c|c|c|}
$\begin{array}{c}\text { Matsumori } \\
\text { Y et al. }\end{array}$ & $\begin{array}{c}\text { Neurobiology of } \\
\text { Disease }\end{array}$ & $\begin{array}{l}\text { Male adult Sprague-Dawley rats (2.5 months of } \\
\text { age, 230-0280 g) from Charles River Laboratory } \\
\text { (152] 2006 }\end{array}$ \\
$\begin{array}{l}\text { (Wilmington, MA) were used for all experiments } \\
\text { and were housed in the institutional standard } \\
\text { cages }(412519 \mathrm{~cm} ; 2 \text { rats per cage) before the } \\
\text { procedures. }\end{array}$
\end{tabular}

The current findings indicate that while APP overexpression does provide some histological neuroprotection following MCAO in rats, this does not translate into significant functional benefit. We suggest that while increased APP expression is protective acutely after stroke,the subsequent accumulation of Ab peptides in the brain may impede, and possibly worsen, functional outcome and recovery.

Unilateral ischemic SMC lesions enhanced performance of a new motor skill task with the less-affected forelimb compared with sham operates.

In the present study, quantitative analysis indicates that CA1 pyramidal neurons undergo dendritic plasticity change after ischemia. A significant outgrowth occurs in the apical dendrites at Is $24 \mathrm{~h}$, which mainly results from the dendritic sprouting in the middle segment. In addition, many neurons display dendritic disorientation after ischemia with some basal dendrites coursing to the apical dendrite territory, and vice versa. These results demonstrate an ischemia-induced dendritic plasticity in CA1 neurons within 48 h after transient forebrain ischemia.

We have demonstrated a presynaptic hyperexcitability at the CA3-CA1 synapses following ischemic insult, and this enhanced response is $\mathrm{Ca} 2+$ dependent. This ischemiainduced presynaptic hyperexcitability may at least partially account for the increased extracellular glutamate and the postsynaptic anoxia-LTP.

The main findings of this study are that postischemic EE combined with spatial learning increased DG neurogenesis and the neural stem/progenitor cell pool, enhanced neuronal differentiation, restored the perturbed DG immature neuroblast production 


\begin{tabular}{|c|c|c|}
\hline $\begin{array}{c}\text { Briones TL } \\
\text { et al. [59] } \\
2006\end{array}$ & $\begin{array}{c}\text { Experimental } \\
\text { Neurology }\end{array}$ & $\begin{array}{l}\text { Adult male Wistar rats } 3-4 \text { months of age (with } \\
\text { mean body weight of } 325 \mathrm{~g} \text { ) were used in the } \\
\text { study and transient global cerebral ischemia was } \\
\text { induced by the four-vessel occlusion method } \\
\text { as previously described. Wistar rats were used } \\
\text { in the present study since this rat strain is } \\
\text { commonly utilized in cerebral ischemia because } \\
\text { it provides a good model for examining cerebral } \\
\text { blood flow and metabolism. }\end{array}$ \\
\hline
\end{tabular}

Hwang IK Journal of the et al. [41] Neurological 2006

\section{Sciences}

This study utilized the progeny of Mongolian gerbils (Meriones unguiculatus) obtained from the Experimental Animal Center, Hallym University, Chunchon, South Korea. The animals were housed at constant temperature (23-C) and relative humidity (60\%) with a fixed $12 \mathrm{~h}$ light/dark cycle and free access to food and water.
Dahlqvist P. European Journal et al. [145] of Neuroscience 2004

Before operation male Sprague-Dawley rats (7-8 weeks old;B \& K Universal Laboratory, Sollentuna, Sweden) were group housed four to five per cage in standard laboratory cages (595X380X200mm) at a temperature of $20-21^{\circ} \mathrm{C}$ with lights on 06:00-18:00h and with free access to water and food(standard rat chow).

Dahlqvist P. European Journal Before operation male Sprague-Dawley rats et al. [145] of Neuroscience 2004

(7-8 weeks old; B \& K Universal Laboratory, Sollentuna, Sweden) were group housed four to five per cage in standard laboratory cages $(595 \times 380 \times 200 \mathrm{~mm})$ at a temperature of $20-21^{\circ} \mathrm{C}$ with lights on 06:00-18:00h and with free access to water and food(standard rat chow).

\begin{tabular}{c|c} 
YOSHIOKA & Pharmacological \\
et al. [84] & Research \\
2002 & \\
\hline
\end{tabular}

The main findings of the present study are that: (1) ischemic injury and EC housing resulted in synaptic and dendritic changes in the hippocampal area adjacent to the site of injury, and (2) EC housing-induced synaptic and dendritic changes were accompanied by enhanced functional recovery after cerebral ischemia. Our results showed that transient global cerebral ischemia and behavioral experience in the complex environment independently resulted in increased number of synapses per neuron, and increased volume of dendritic processes and surface area of dendritic membrane per neuron in the CA2CA3 of the hippocampus

Our results suggest that the impairment of AC-I may occur in the hippocampal CA1 region without any neuronal loss at early time after transient forebrain ischemia and that AC-I may be associated with impairment of neurodevelopment and neuroplasticity including learning and memory in the hippocampus after transient ischemic insult.

The main finding of this study is that postoperative housing in an EE restored the spatial memory impairment after MCAo in rats. Furthermore, EE housing extinguished the association between poor spatial memory and large infarct volumes that was seen after MCAo in deprived rats

The main finding of this study is that postoperative housing in an EE restored the spatial memory impairment after MCAo in rats. Furthermore, EE housing extinguished the association between poor spatial memory and large infarct volumes that was seen after MCAo in deprived rats

Ibudilast protects nerve cells from death due to cerebral ischemia byinhibiting Ca2+ influx into cells or by inducing favorable changes in cerebral metabolism in addition to uncertain mechanism(s). 


\begin{tabular}{|c|c|c|}
\hline $\begin{array}{c}\text { Farrell, R. } \\
\text { et al. [148] } \\
2001\end{array}$ & Neuroscience & $\begin{array}{l}\text { This experiment used 84, 4-5-month-old female } \\
\text { Mongolian gerbils (Meriones unguiculatus) } \\
\text { weighing 50^76 g (High Oak Ranch, Baden, ON, } \\
\text { Canada). Animals were housed in groups of five } \\
\text { in standard plastic laboratory cages on a 12/12-h } \\
\text { light/dark cycle. All experimental manipulations } \\
\text { were performed during the light phase. Food } \\
\text { and water were freely available. Three days after } \\
\text { surgery/sham occlusion (see below) animals were } \\
\text { housed either five per cage (enriched condition) } \\
\text { or singly (non-enriched condition) }\end{array}$ \\
\hline
\end{tabular}

Mori K. Behav Brain Res. Adult male Wistar rats (280-360 g b.w. and et al. [83]

2001

Briones et

al. [153]

2000
Biological

research for

nursing
8-13 weeks old) were used (Slc:Wistar:ST,

Shizuoka Laboratory Animal Center,

Hamamatsu, Japan). The animals were housed in a room with a 12-h light (07:00-19:00 h)dark (19:00-07:00 h) cycle and were allowed food and water freely. In each experiment, different rats (five-ten) were used except in the behavioral studies. In the behavioral studies, a Y-maze test was conducted 1 day after the open field test sing the same rats.

Thirty-eight adult female Wistar rats age 65 to 75 days old and weighing 275 to $350 \mathrm{~g}$ at the time of surgery were included in the study. Female animals were used in this study because it has been shown that they are more sensitive to plastic changes (Woolley and McEwen 1994). All animals were housed individually in a temperature-controlled environment $\left(25^{\circ} \mathrm{C}\right)$ with free access to standard rodent food and water. The animals were handled daily and maintained on a reverse light-dark cycle (lights on at 6:00 PM and off at 6:00 AM).
The main findings of this study were that environmental enrichment attenuated the behavioral abnormalities associated with IP but paradoxically, enrichment increased the loss of CA1 neurons

These results suggested that reduction of LTP in the perforant path-dentate gyrus synapses, a gate for novel information, might result in faulty passing of information to the CA3 and/or CA1 region resulting in memory dysfunction. In contrast, restoration of LTP in the perforant path-dentate gyrus by administration of aminoguanidine might open the gate to novel information resulting in the successful passage of information to the CA3 and/ or CA1 region. Since LTP in mossy fiberCA3 synapses was not influenced by 4 -VO or administration of aminoguanidine, processing of novel information in the CA3 region instead of the CA1 region via the dentate gyrus might contribute to the prevention of memory dysfunction.

Our results showed that ischemic rats exposed to an enriched environment performed as well as controls in the spatial learning task. In comparison, ischemic rats housed in standard environment, although able to learn, demonstrated a slower rate of learning and a higher asymptotic level of learning (did not reach control levels even on days 5 and 6 ) in both swim latency and directional heading error. 
Kiprianova

l et al. [34] 1999
Exp Neurol.

Global cerebral ischemia was achieved in adult male Wistar rats (450-600 g) with four-vessel occlusion under halothane/nitrous oxide. Both vertebral arteries were coagulated, followed by the transient occlusion of both common carotid arteries for $10 \mathrm{~min}$. In sham-operated control animals, both vertebral arteries were coagulated and the carotid arteries were exposed, but not occluded. The left femoral artery was cannulated with PE-50 polyethylene tubing for continuous monitoring of arterial blood pressure and blood sampling for analysis of arterial blood gases. The temperature was recorded with a rectal thermistor and maintained between $37.0^{\circ}$ and $37.5^{\circ} \mathrm{C}$ with a feedback-controlled heating lamp. Animals were returned to their cages after the surgical procedure with free access to water and standard rat chow. BDNF was administered by an osmotic minipump which was implanted after the reopening of the carotid arteries.

\begin{tabular}{|c|c|c|}
\hline $\begin{array}{c}\text { Stroemer } \\
\text { et al. [89] } \\
1998\end{array}$ & Stroke & $\begin{array}{l}\text { Nonfasted male SHR (weight, } 260 \text { to } 300 \\
\text { g) were anesthetized with halothane ( } 4 \% \\
\text { induction/1\% maintenance), placed on a heating } \\
\text { pad, and given an antibiotic (streptomycin, } 0.10 \\
\mathrm{~mL}, 150 \mathrm{mg} / \mathrm{mL} \text { IP). SHR were used to ensure } \\
\text { constant infarction volume and placement } \\
\text { because of poor collateral circulation and } \\
\text { consistent vascular anatomy. }\end{array}$ \\
\hline $\begin{array}{l}\text { Mizumori } \\
\text { SJ et al. } \\
\text { [123] } 1995\end{array}$ & Behav Neurosci. & $\begin{array}{l}\text { Nineteen Wistar male rats (175-225 g; 6-8 } \\
\text { weeks old; Hilltop, PA) were housed, } 2 \text { each, to a } \\
\text { hooded, ventilated cage in animal quarters that } \\
\text { were temperature and humidity controlled and } \\
\text { on a controlled light-dark cycle. They were fed ad } \\
\text { libitum and had free access to water for } 7 \text { days } \\
\text { prior to the surgical procedure. }\end{array}$ \\
\hline
\end{tabular}

We described for the first time improved cognitive functions associated with a recovery of synaptic transmission after transient forebrain ischemia. These data provide further evidence for the neuroprotective effects of BDNF after lesions of the adult brain and indicate a therapeutic potential in acute neurovascular disease
D-AMP treatment in concert with performance of behavioral tasks can selectively up regulate neurite growth in those neural circuits able to subserve the behavioral function tested, despite the loss of the original pathways. Thus, physical therapy during the effective window of D-AMP treatment may improve recovery in patients with cortical ischemia and trauma.

The results of this study provide the first evidence that the ischemic hippocampus undergoes long-term functional reorganization that might contribute to the initially impaired acquisition of a spatial task 


\section{Discussion}

Generally, the reviewed articles were based on the mensuration of the influences, in the prognosis of the cerebral ischemia, of some predetermined exogenous substances, some already known endogenous substances or of the behavior of the sample studied. Nevertheless, to provide better analysis and following the progress of the investigation, the articles that focused on these three main themes were discussed in other themes that they also have pointed interesting views, such as Enriched Environment (EE), Endogenous Conformations and The Effects of Motor Activities Practice on Neural Plasticity.

\section{Endogenous Conformations}

There are several unique mechanisms developed by the body, seen in the present study, which are important to the control of the cerebral damage caused by ischemic processes, once ischemia induces changes in neuronal excitability and alters dendritic spines within hours. [11-13, 6] The alteration of dendritic arborization directly affects the number of spines, and thus the function of the neurons [14]. It was proved that one of the main factors underlying learning and memory formation at the cellular level is long-term potentiation (LTP), $[15,16,40]$ considered a major synaptic mechanism underlying hippocampus-dependent learning and memory, [17-19, 34] which is N-methyl- D -aspartate (NMDA) receptor and voltage dependent and requires an increase in intracellular concentrations of calcium ions. [20, 21, 48]

One mechanism possibly contributing to sensorimotor deficits and recovery is an altered balance between excitatory and inhibitory neurotransmitter receptors [22]. Previous work suggests that blockade of a 2 adrenoceptors enhances sensory responses at the spinal cord level, possibly contributing to the improved performance of ischemic rats in a test assessing tactile/proprioceptive limbplacing reactions $[23,22]$. Besides, there is significant neuroprotection in the absence of either the innate immune receptor
PirB or two of its $\mathrm{MHCl}$ ligands $\mathrm{Kb}$ and $\mathrm{Db}$ by using in vivo and in vitro ischemia models6. It was also demonstrated that Rho/Rho-kinase pathway is involved in the modulation of N-methyl-D -aspartate (NMDA) receptor function, [24, 25, 73] which may be associated with learning and memory processing and disruption of the gene for NR2B in mice causes perinatal lethality. $[26,73]$

Another important endogenous molecule that significantly contributes to the learning recovery in post-ischemic processes is the BDNF (Brain Derived Neurotrophic Factor), which is one of a family of neurotrophins that influences neuronal proliferation, survival, and differentiation $[27,28]$ as a result of binding to its tyrosine kinase receptor and subsequent downstream activation of several signal transduction pathways, [28] in addition to has pleiotropic effects on modulating activity-dependent forms of synaptic plasticity, neuronal survival, neuronal development, dendritic arborization and axon growth. [29, 30, 33]

It has been speculated that BDNF is involved in the maintenance of LTP, $[31,32,34]$ fact that occurs because a decrease in BDNF expression can cause neuronal death or axonal damage. [33] It was demonstrated that intracerebroventricular infusion of BDNF can restore almost completely both synaptic transmission and memory capacity [34] and that strategies that increase BDNF broadly within the nervous system, such as exercise or BDNF infusion, may enhance neuroplasticity processes in multiple neuronal systems involved in motor relearning during stroke rehabilitation. [28] This motor learning increases BDNF levels in the cortex, which may contribute to cortical map reorganization, increased synaptogenesis, enhanced dendritic spine formation and branching, and other forms of neuronal plasticity implicated in recovery after stroke. $[35-38,28]$ This occurs because BDNF elevates intracellular $\mathrm{Ca}^{+2}$ in hippocampal neurons, stimulates phospholipase C/protein kinase C pathways, and increases the number of calbindin containing neu- 
rons in hippocampal slice cultures. Several lines of evidence indicate that calcium ions play a central role in the delayed neuronal death observed in the CA1 region of the hippocampus after transient forebrain ischemia. $[39,34]$ It was also exposed that the mechanism of recovery of spatial learning and memory may be relevant to BMSCs (Bone Marrow Stromal (ells) transplantation by mediating the expression of BDNF and P75NTR, after transplanted the BMSCs. [33]

There is, also, other metabolic pathways necessary to combat the cerebral ischemia, like that present when chronic hypoperfusion, as in CADASIL (Cerebral autosomal dominant arteriopathy with subcortical infarcts and leukoencephalopathy), might induce compensatory brain plasticity. [40] Besides, significant increases of AC-I immunoreactivity and its protein level were detected at $3 \mathrm{~h}$ after ischemic insult. This result may be associated with the compensatory mechanisms to ischemic damage. [41] Among these subtypes of AC (Andenilato Cyclase), AC-I and AC-VIII are mainly detected in brain and play an important role in signal transduction underlying some forms of learning and memory function. $[42,41]$ The mechanisms underlying this increased plasticity may include release of neurotrophic factors. [40] As an example of these factors, there is the transcription factor, $\triangle$ FosB, which is cumulatively and persistently expressed in response to repeated neuronal activation. $[43,44]$ It was proved that it increased reliance on the intact forelimb in tests of coordinated forelimb movements, once that unilateral lesions increased FosB/ $\triangle$ FosB neuronal density in layer II/III of remaining SMC (Sensoriomotor Cortex) near the infarct after impaired forelimb training; however, early intact forelimb training reduced this expression. [44] The glutamate, also, is very important because plays an important role in dendritic development via activation of AMPA and NMDA receptors, [45, 46, 47, 14], and, furthermore, an increased glutamate release is one of the mechanisms leading to neuronal death following ischemic stroke. [48] As an example of an AMPA receptor dependent protein, there is the PICK1 (Protein Interacting with $C$ kinase 1 ), which has been proven to be one of the key proteins in the regulation of synaptic plasticity. [49-51, 60]

A highlighted approach is the contralesional brain compensation after an ischemic damage. Some of the contralesional changes are associated with enhanced ipsilesional function. [52] Following unilateral cerebral damage, humans and other animals develop a compensatory hyper-reliance on the lessaffected body side ipsilateral to the injury. [53, 44] The enhanced ipsilesional function might aid in behavioral compensation but might also make animals more prone to disuse the impaired forelimb, contributing to the phenomenon of learned-nonuse. [54, 52] The intact hemisphere develops an exaggerated disruptive influence over the infarcted hemisphere which is linked with worsened outcome. [55, 44] These findings suggest that the intact hemisphere can negatively impact function of the impaired body side. [44]

It is noted the influences of other endogenous mechanisms, such as TRPM7 (Transient receptor potential cation channel, subfamily $M$, member 7) suppression in hippocampal CA1 neurons in vivo is well tolerated, imparts resilience to ischemic damage, and preserves neuronal function and performance for hippocampus dependent learning tasks after ischemic brain injury.[56] The cationic channels are essential for the transport of ions such as $\mathrm{Na+}$, because the long-lasting enhanced PR (Presynaptic Response) following ischemia may result in a significant enhancement of $\mathrm{Na}+$ influx to the presynaptic terminals, which may play an important role in both $\mathrm{Na}+$ - glutamate transporter - or exocytosis - mediated glutamate release that is detrimental to the postsynaptic neurons. [48] Besides the TRPM7, the HCN1 mRNA was shown to be decreased significantly in the hippocampal CA1 area and neocortex in the chronic ischemic rats with possible features of vascular dementia. Down regulation of 
HCN1 mRNA led to decrease of HCN1 channels expression. It is definite that HCN1 channels play a key role in function of learning and memory. [57] There is, still, the endogenous Nitric Oxide, which plays a critical role in the induction of hippocampal iLTP (post-ischemic LTP). In fact, iLTP is blocked by either L-NAME, a non-selective NOS inhibitor, or 7-NINA, a relatively more selective inhibitor of nNOS. [58] The LTP is considered as one of neural activations for long term memory. [41]

There are studies that suggest that rehabilitation therapies may be able to remodel neuronal circuitry within the injury site and its surrounding region and that such restructuring contributes to "recovery" of function that is compromised by the injury. [59] There are data showing that WM (Willed Movement) training leaded to a larger amount of LTD (Long Term Depression) compared to MCAO (Middle Cerebral Artery Occlusion) rats and EM (Environmental Modifications) rats, and WM training facilited motor recovery after focal ischemia in rats. It can be inferred that a 'therapeutic' effect that might be due, at least partially, to stimulation of LTD-related synaptic neuroplasticity. [60]

It is noted, also, that melanocortins afford a strong neuroprotection against damage consequent to global or focal cerebral ischemia in gerbils and rats. They act by blocking several ischemia-related mechanisms of damage, through the activation of central nervous system (CNS) melanocortin MC 4 receptors, and in a broad therapeutic treatment window. [61-64, 65] This effect occurs through a counteraction of the main ischemia-related, early developed mechanisms of damage, and is associated with long-lasting improvement in functional recovery accompanied by overexpression of Zif268, an immediate early gene required for synaptic plasticity and memory formation and involved in injury repair. [61, 62, 63, 65, 70] Also known as Egr-1, Krox-24, NGFI-A, TIS8 and ZENK, this gene belongs to the early growth response gene family, and the expression of these immediate early genes is de- pendent on synaptic activity and is used as a marker of neuronal functionality. [66-69, 65] Thus, the data showing a significant increase in Zif268 levels in the whole hippocampus of melanocortin-treated animals point to a gain in the number of activated/ functional neurons. [70]

Lastly, a neuronal plasticity involves cytoskeletal remodeling, where the Rho GTPases, a subgroup of proteins from Ras superfamily, are major players, participating in neuritic outgrowth, differentiation, axonal guidance, dendritic spine formation and maintenance. [71, 72, 74] Nevertheless, there is data providing novel information for the importance of Rho-kinase inhibition in improving the deficit of cognition and the ability of spatial learning and memorizing in chronic ischemia. [73] It is important to point, too, that in vitro studies revealed that the Rac1 inhibition(pharmacological and dominant negative mutant) induced neuronal death, and the Rac1 activation (constitutively active mutant) produced neuronal survival. [74]

\section{The role of the exogenous substances}

This systematic review notified the existence of several exogenous substances which, when actuate in many conformations of the organism, are important to the recuperation process provided by cerebral ischemic damages, related to cognitive impairment and neuronal death. [75] Among these, there are the Ceftriaxone, the Hydrogen Sulfide, the new pyridoindole antioxidant SMe1EC2, the Piracetam and the D-amphetamine sulfate.

The Ceftriaxone, a $\beta$-lactam antibiotic, selectively increases GLT1 expression and the functional capacity of glutamate uptake. [76, 10] On the other hand, the Piracetam, a gamma-aminobutyric acid derivative, attenuated apoptotic-like changes and neuron losses and reversed the shift in the expression pattern apoptosis-related proteins (BAX and P53) induced by ischemia in the cortex. [75] In experimental stroke, ceftriaxone injected prior to the onset of middle cerebral artery occlusions (MCAo) has been 
found to reduce infarct volume. $[77,10]$ In a similar way, piracetam could facilitate the synaptic transmission in hippocampus.75 Some findings suggest that the neuroprotective effects of ceftriaxone, in particular its ability to reduce infarct volume, may be maximized when ceftriaxone is injected prior to ischemia, enabling astrocytic glutamate uptake to be enhanced at the onset of the stroke. [10] This Ceftriaxone effect is similar to the mechanism of facilitating the electrophysiology in rat brain of piracetam, which may be explained by the effects of the increase of the content of glutamate, the key excitory neurotransimitter in central nervous system and related to the excitory synaptic transmission and neuron plasticity. [78, 75] Nevertheless, some other substances do not show a direct relation with the glutamate, such as the pyridoindole antioxidant SMe1EC2, which presumably contributes to the preservation of the neuronal cell membrane and to its permeability, and further by its inhibitory effect on carbonylation of proteins mediated by conditions involving oxidative stress, and thus SMe1EC2 might protect neurons from damage of membrane lipids and protein receptors. [79]

Other antioxidant substances play an important role on the post-ischemic damages recuperation and on the protection of endogenous mechanisms that control the spread of these damages, such as LTP. The Quercetin, for example, protects against LTP changes in the hippocampus induced by chronic cerebral ischemia. [80] Besides the Quecertin, the effect of the DDPH, 1-(2, 6-dimethylphenoxy)-2-(3, 4-dimethoxyphenylethylamino) propane hydrochloride, categorized as a competitive $\alpha 1$-adrenoceptor antagonist, facilitates the synaptic plasticity, which might be related, at least, to its antioxidant property and the up-regulating expression of NR2B.81 Similar as the quercetin can alter the cognitive deficits induced by different methods including transient cerebral ischemia, $[82,80]$ the DDPH was shown to significantly attenuate the neuronal damage and to ameliorate the cognitive deficits. [81]
Moreover, it was noted the influence of specific inhibitors in suppressing the expansion of the post-ischemic damage. Behavioral performance, i.e. Y-maze and contextual fear conditioning, was impaired following transient cerebral ischemia, and the impairment was ameliorated by the administration of aminoguanidine, a relatively selective iNOS inhibitor, [83] for example. Other notable substance involved in this inhibition process is the ibudilast, a phosphodiesterase inhibitor. It protects nerve cells from death due to cerebral ischemia by inhibiting $\mathrm{Ca} 2+$ influx into cells or by inducing favorable changes in cerebral metabolism in addition to uncertain mechanism(s). [84]

Studies suggests, still, that the Nitric oxide (NO) is an intercellular retrograde messenger, originally described as an endothelial relaxation factor, which has been shown to be involved in several physiological processes such as hippocampal long-term potentiation (LTP), plasticity, learning, and memory. $[85,86,58]$ The levels of NO metabolites, NOx, were increased following transient cerebral ischemia. [83] Experimental studies have shown that ZNS (Zonisamide) inhibits NO synthase in the hippocampus following NMDA administration suggesting a possible neuroprotective effect via a reduction of NO formation. $[87,58]$ iNOS inhibitors seem to be more appropriate for clinical targets in ischemic insult. In the previous reports, the effects of nNOS on learning and memory were still controversial. [83] Besides, studies indicate that NOS inhibitors do not modify the iLTP once established indicates that NO production is necessary for the induction of this form of pathological synaptic plasticity, but not for its maintenance. [58]

The GAP-43 is a nervous tissue specific protein, which is highly expressed in neurons during development and nerve regeneration, and has been implicated in neurite outgrowth, long-term potentiation, signal transduction and neurotransmitter release. [88] Some exogenous substances could elevate the expression of this protein, such as the D-ampheta- 
mine sulfate (D-AMP). Since an important outcome measure is recovery of function, it is meaningful to correlate the expression of GAP-43 and synaptophysin with functional outcome in D-AMP-treated compared with vehicle-treated rats. [89] Beyond this, there is, also, the $\mathrm{H}_{2} \mathrm{~S}$, that could inhibit the edema around pyramidal neurons and the nuclear shrink induced by ischemia, promote the expression of GAP-43 in the CA1 region of post-ischemic hippocampus, and decrease the injury of neurons caused by ischemia. [88] D-AMP treatment improves behavioral recovery not only in the sensorimotor task of the forelimb behavior but also in the spatial memory tasks. [89] The spacial memory recovery is provided, also, by the atorvastatin administration. Findings suggest that acute ATV administration after cerebral ischemia protects against morphological and functional brain damage and facilitates long-term spatial-learning and memory recovery by a GluN2B NMDA receptor subunit-dependent mechanism. [9]

\section{Behavioral determinants}

It was shown that the hippocampal synaptic plasticity is considered to be the cellular basis of learning and memory in the brain. $[90,92]$ For example, in relation to the Gabaergic receptor, altered receptor binding in the hippocampus would contribute to spatial learning deficits. [22] There are findings indicating, also, that a different function for HCN1 channels is found in hippocampal CA1 neurons. Deletion of the HCN1 channel in forebrain neurons results in an unexpected exchange of spatial learning and memory. [91, 57] Besides, it was demonstrated that, after a transient cerebral ischemia, the number of CA1 neurons in the bilateral hippocampi decreased with increased time of occlusion of the bilateral carotid arteries. [92]

There is data that directly relate the hippocampal conformations to the post-ischemic behavioral consequences, because hippocampal [3H]AMPA receptors might be involved in compensatory behavior developed by ischemic rats in order to overcome spatial learning deficits. [22] Results show, still, that the HCN1 channels play a key role in function of learning and memory. Both down regulation of HCN1 mRNA and knockout of HCN1 could lead to impairment of learning and memory function. [57] Data also suggests that the recovery of spatial learning in a group of rats after 20 days post ischemic procedure might be due to functional compensation for the ischemia-induced damage to hippocampal CA1 neurons by neural networks of learning in the extra-CA1 regions.[92]

\section{The role of the endogenous substances}

A variety of endogenous substances were observed, beyond those exogenous ones, which act by different mechanisms. These substances have an extremely importance to the complete recovery of patients affected by processes of oxygen deprivation. Among these, it is known the Ulinastatin, the melanocortins, the Netrin-1 protein, the amyloid precursor protein (APP), the hormones - progesterone and erythropoietin - and the synthetic form of this one, the darbepoetin alfa.

Melanocortins with the adrenocorticotropin/amelanocyte-stimulating hormone (ACTH/a-MSH) sequences, as well as shorter fragments and synthetic analogs, have a protective and life-saving effect in animal and human hypoxic conditions. [93-97, 65] MC3 and MC4 are the predominant melanocortin receptor subtypes expressed in the CNS. [70] That short-term treatment of ischemic stroke with nanomolar amounts of the melanocortin NDP-a-MSH (agonist at MC 1, MC 3, MC 4 and MC 5 receptors) $[61-63,65]$ produces long-lasting functional recovery associated with overexpression of the activity-dependent gene Zif268 in the hippocampus. [65] Thus, there is data that give direct evidence, for the first time, of the neuroprotective effect of melanocortin MC4 receptor agonists. [70] Besides, Zif268 upregulation in the hippocampus of melanocortin-treated animals could have had 
a key role in learning and memory recovery after stroke. [65]

Among the hormones involved with the enhancement of neuroplasticity, there is the Erythropoietin (EPO). The EPO gene is regulated by hypoxia inducing factor (HIF), where it stimulates erythropoiesis and proliferation of parenchymal cells. [98-100, 102] In the brain, EPO is neuroprotective and has also brain restorative properties in different models of acute neuronal death and neurodegenerative diseases, through effects on neurons and astrocytes by multimodal actions. [101, 102] Concomitantly, it was noted the influence of the synthetic form of the Erythropoietin, the Darbepoetin alfa, whereupon findings suggest that erythropoietins such as Darbepoetin alfa may improve cognitive performance in humans by activating the NOS signaling pathway. [103] Like its analogues covalents, we conclude that intravenous EPO administration after global ischemia does not protect against ischemic brain damage, but protects against loss of synaptic function important for working and spatial memory. [102] Other hormone involved in the enhancement of the neuroplasticity in patients affected by cerebral ischemic processes is the progesterone, which has several positives characteristics in relation to cerebral activity, because the progesterone increases GAP-43 and SYP levels in the CA1 region of the male rat hippocampus. In conjunction with previous studies, it appears that PROG-induced increases in the cognitive function of rats may be influenced by the effect of PROG on hippocampal synaptogenesis and synaptic plasticity. [104]

Among the important proteins in the ischemic process recovery, there are: Rac-1, Netrin 1 and BDNF. In vitro and in vivo findings suggest that the inactive state of Rac is present in neuropathological condition, even implying abnormal neuronal survival in a part of the neuronal population during the acute and middle phase after ischemia. [74] The intrahippocampal injection of netrin-1 dosedependently and significantly ameliorated memory impairment and improved synaptic dysfunction. [8] Results provide the first direct demonstration that BDNF is crucial for mediating the motor relearning that takes place as a result of poststroke rehabilitation. [28] It is also possible that netrin1 in some ways could act like growth factors including brain-derived neurotrophic factor (BDNF). [105, 8] Stroke rehabilitation strategies that increase BDNF broadly within the nervous system, such as exercise or BDNF infusion, may enhance neuroplasticity processes in multiple neuronal systems involved in motor relearning during stroke rehabilitation. [28] Besides these cited proteins, there is a specific class of proteins, the glycoproteins, highlighting two involved in neuronal plasticity process. Firstly, there is the Ulinastatin -a urinary trypsin inhibitor-, which became an endogenous positive factor, actuating in the neuroplasticity once it is considered cytoprotective against I/R injury in the liver, intestine, kidney, heart and lung through its anti-inflammatory activity. [106, 107, 154] Furthermore, there is the Amyloid precursor protein (APP) is a transmembrane glycoprotein, which is widely expressed in the brain. APP and its products are proposed to have a number of important physiological roles in the nervous system, including development, synaptic function and plasticity, and cellular response to stress. [108, 109] Nevertheless, there are findings indicating that while APP overexpression does provide some histological neuroprotection following MCAO in rats, this does not translate into significant functional benefit. [109]

\section{The effects of motor activities practice on neural plasticity}

The neuroplasticity involves various ways to establish that new connections in cortical networks could be effectuated, providing a new information flow. Studies suggest that motor learning mechanisms may be operative in stroke recovery and possibly reinforced by rehabilitative training. To maximize functional rehabilitation in patients with stroke, it is necessary 
to explore the basic changes in brain plasticity in response to different treatment approaches. [121]

In view of the importance of the way that the approach is going to be made, it is noted that the enhancement of the cortical reorganization can be done by motor experience. These experiences shall be effectuated in a way to follow a specificity, because studies conclude that skilled motor can induce brain plasticity after brain ischemia. [120] In relation with it, it was performed a new way to improve the motor ability following a cerebral ischemia, such as the Willed-movement (WM) training, which is defined as a voluntary motor training through which an individual pays attention to a goal and makes an effort to accomplish it. [110, 60] WM therapy $[111,60]$ involves more coordinated activities of the whole body and limbs. [60] Nevertheless, some studies show that in a traumatic brain injury model, animals receiving voluntary exercise early post-injury (days 0-6) were found to have reduced expression of plasticity-related proteins in the hippocampus and worsened water maze performance compared to animals exercised between 14 and 20 days after injury. [113, 112] Despite this evidence, data also clearly showed that WM training leaded to a larger amount of LTD compared to MCAO rats and WM training facilitated motor recovery after focal ischemia in rats. [60] This apparent contradiction is explained when it is pointed that although exercise can be beneficial, learning motor skills results in neuronal structural and functional plasticity in the motor cortex and cerebellum that is not found with simple exercise or repetition of previously learned skill, [114-116, 112] since learning may more effectively induce activity-dependent plasticity than mere use, at least in some of the brain regions that mediate motor movements. [112] For example, the primary motor cortex- M1 is involved in the process of motor learning and that learning-associated activity in M1 can be greater in magnitude and areal extent than the activity associated with simple motor use either in healthy or in lesion conditions. [117-119, 120]

Studies prove the occurrence of structural changes in the brain after the ischemia. The structural changes should require the synthesis and/or redistribution of various neuronal proteins necessary for motor learning. [120] They are, generally, beneficial, because the successful functional recovery after ischemic stroke seems to be linked to reemergence of a lateralized motor network combined with plasticity in bilateral somatosensory association areas and contralesional SII. [121] It was, nevertheless, observed no significant modification in protein expression in undamaged cortex. [120] Thus, such changes may be the natural evolution of functional recovery but may also be enhanced by the given treatment. [121] However, in patients with stroke, the underlying structural pathologic condition resulting from the ischemic episode will recruit additional regions or networks to compensate for the functional deficit, [122, 121] because the cellular activity in multimodal association cortex undergoes long-term functional reorganization. [123] Thus, a general principle of neuronal responses to brain injury may include the reorganization of representational systems. Such a process may reflect an alternate neurocognitive strategy for learning new information. [123]

A completely learning recovery, after an ischemic process, depends of several factors, including the stroke severity and type/intensity/duration of treatment. Skilled rehabilitation would be a good choice, even after a severe stroke and restricting the compensatory mechanisms during rehabilitation might be pivotal for functional improvement. [120] It is also known that early motor training seems essential for successful recovery, and motor learning mechanisms may be operative during spontaneous stroke recovery and interact with rehabilitative training. [112, 124, 125, 126, 127, 128, 121] Besides, many studies finding beneficial effects of exercise after injury used a regimen in which the animal 
experienced the exercise before the application of the injury. [129-131, 112]

\section{Enriched Environment}

Environment, social interaction, and physical activity are determinants of functional outcome after experimental cerebral infarction. [132-135, 152]. Besides, exposure to complex spatial environments or environmental enrichment causes increased dendritic growth and spine formation, synaptogenesis and increased expression of growth factors in the cortex and hippocampus of both normal and injured animals. [136-143, 148]

It was showed that $\mathrm{CCH}$ (Chronic cerebral hypoperfusion) led to cognitive impairment in rats and exposure to an EE (Enriched Environment) attenuated the cognitive impairment induced by $\mathrm{CCH}$ by improving synaptic plasticity. [144] Besides, studies found that postoperative housing in an EE significantly attenuates the long-term spatial memory impairment induced by MCAO rats. [145] Several studies have shown that an EE can enhance learning and memory, enhance synaptic plasticity not only in lesioned rats but also in nonlesioned rats. [146, 147, 144] An important aspect of the enrichment environment is that animals are continuously exposed to a varied environment. During enrichment, objects were moved into different locations in the cage and the presence of other animals ensured changing sensory-motor stimulation. [148] Studies showed that $\mathrm{CCH}$ leads to decreased levels of NMDAR1, which are restored by an EE. [149, 144] Similar to this, for rodents, post-ischemic housing in an enriched environment (EE) improves functional outcomes and increases transcriptional factor expression including NGF-IA and IB expressions, enhances brain-derived neurotrophic factor (BDNF) mRNA and protein expression, decreases serotonin receptor expression. [150, 151, 152] It is conceivable that increased expression of growth factors or cell survival genes (e.g. Bcl-2) might 'rescue' CA1 neurons that otherwise would go on to die. [148]
However, studies made in animals subjected to ischemic preconditioning (IP) or ischemic tolerance, showed that the environmental enrichment did not attenuate the delayed loss of CA1 neurons after ischemic preconditioning. [148]

The studies aimed to analyze in which aspects the EE is more beneficial. For example, a related experiment using a focal ischemia model demonstrated an increase in infarction volume when rats were put into an enriched environment plus training on several motor tasks beginning $24 \mathrm{~h}$ after ischemia. [148] The inclusion of cognitive learning also simulates occupational therapy in humans. According to our results, EE/learning significantly enhanced neuronal differentiation and neurogenesis in both sham surgery and ischemic rats compared to standard housing. [152] It is questioned to what extent this improved behavioral outcome is due to recovery of lost functions or to compensation for lost functions is difficult to ascertain. However, in view of evidence of morphological plasticity and the absence of evidence of alternative learning strategies (swim latency and directional heading error were similar to controls) in ischemic animals exposed to enriched environment, it is likely that environmental enrichment facilitates recovery of lost function rather than compensation. [153]

\section{Conclusion}

This revision possible to infer that the brain plasticity allows the recovery of neurologic adult patient, even partially, and the interaction with the environment can promote structural and functional changes in the central nervous system. In addition, physical rehabilitation and endogenous and exogenous factors allow an increasingly efficient adjustment of motor responses issued. This means that this type of treatment, when properly developed, effectively contributes to neuroplasticity, and therefore allows the reintroduction of learning in patients suffering from cerebral ischemia. 
One can see, however, that the human brain constantly undergoes structural and chemical changes, such as the regulation of neuronal plasticity after cerebral oxygen deprivation processes, and this is one of the main reasons that affects the clarify of its mechanisms. Therefore, it is necessary that further researches, especially in humans, could be performed so that there is a better understanding of neuroplastic changes in the neuronal recovery.

\section{Acknowledgements}

We are grateful to the Suicidology Research group - Federal University of Ceará (UFC) / National Council for Scientific and Technological Development (CNPq). We would also like to thank the Scientific Writing Lab (LABESCI)-Faculty of Medicine, Federal University of Cariri (UFCA), and to the Laboratory of Scientific Methodology and Scientific Production (LAPESCI)-Faculty of Medicine, Estácio.

\section{Role of funding source}

We have no foundation source.

\section{Conflict of interest}

The authors have no conflicts of interest or financial ties to report.

\section{References}

1. Jian H, Yi-Fang W, Qi L, Xiao-Song H, Gui-Yun Z. Cerebral blood flow and metabolic changes in hippocampal regions of a modified rat model with chronic cerebral hypoperfusion. Acta neurologica Belgica. 2012.

2. Ott BR and Saver JL (1993) Unilateral amnesic stroke, six new eases and a review of the literature. Stroke 24, 1033-1042.

3. Shaw PJ, Bates D, Cartlidge NE, Heaviside D, French JM, Julian DG and Show DA (1987) Neurologic and neuropsychological morbidity following major surgery: Comparison of coronary artery bypass and peripheral vascular surgery. Stroke 18, 700707.

4. Townes BD, Bashein G, Hornbein TF, Coppel B, Goldstein DE, Davis KB, Nessly ML, Bledsoe SW, Veith RC, Irey TD and Conen MA (1989) Neurobehavioral outcomes in cardiac operations. J Thorac Cardiovasc Surg 98, 774-782.

5. MacLellan, C.L., Keough, M.B., Granter-Button, S., Chernenko, G.A., Butt, S., Corbett, D., 2011. A critical threshold of rehabilitation involving brain-derived neurotrophic factor is required for poststroke recovery. Neurorehabil. Neural Repair 25, 740-748.

6. Adelson J.D. et al. Neuroprotection from Stroke in the Absence of $\mathrm{MHCl}$ or PirB. 2012. Neuron Report. Neuron 73, 1100-1107.

7. Yanlin Wang, Songbo Yang, Huili Zhang, Guangming Gong, Qin Jie, Yuming Xu. Transplantation of bone marrowderived stromal cells to chronic cerebral ischemia rats on the influence ofCognitive function and proteins Nogo-A and NgR expression in the hippocampus. Life Science Journal. 2012; 9(1): 733-9.

8. Bayat M, Baluchnejadmojarad T, Roghani M, Goshadrou F, Ronaghi $A$ and Mehdizadeh $M$ et al. Netrin-1 improves spatial memory and synaptic plasticity impairment following global ischemia in the rat. Brain Research 1452 (2012) 185-194.

9. Gutierrez-Vargas JA, Muñoz-Manco JI, Garcia-Segura LM and Cardona-Gómez GP. GluN2B N-Methyl-D-aspartic acid Receptor Subunit Mediates Atorvastatin-Induced Neuroprotection After Focal Cerebral Ischemia. Journal of Neuroscience Research 92: 1529-1548 (2014)

10. Kim S.Y. and Jones T.A. The effects of ceftriaxone on skill learning and motor functional outcome after ischemic cortical damage in rats. Restorative Neurology and Neuroscience 31 (2013) 87-97

11. Brown, C.E., Li, P., Boyd, J.D., Delaney, K.R., and Murphy, T.H. (2007). Extensive turnover of dendritic spines and vascular remodeling in cortical tissues recovering from stroke. J. Neurosci. 27, 4101-4109.

12. Brown, C.E., Wong, C., and Murphy, T.H. (2008). Rapid morphologic plasticity of peri-infarct dendritic spines after focal ischemic stroke. Stroke 39, 1286-1291. 
13. Takatsuru, Y., Fukumoto, D., Yoshitomo, M., Nemoto, T., Tsukada, H., and Nabekura, J. (2009). Neuronal circuit remodeling in the contralateral cortical hemisphere during functional recovery from cerebral infarction. J. Neurosci. 29, 10081-10086.

14. Ruan Y.-W. et al. Dendritic plasticity of CA1 pyramidal neurons after transient global ischemia. Neuroscience 140 (2006) 191201

15. Rioult-Pedotti MS, Friedmann D, Donoghue JP. 2000. Learninginduced LTP in neocortex. Science. 290:533-536.

16. Frantseva MV, Fitzgerald PB, Mo“ller B, Daigle M, Daskalakis ZJ. 2008. Evidence for impaired long-term potentiation in schizophrenia and its relationship to motor skill learning. Cereb Cortex. 18:990-996.

17. Bliss, T. V., and G. L. Collingridge. 1993. A synaptic model of memory: Long-term potentiation in the hippocampus. Nature 361: 31-39.

18. Roush, W. 1997. New knockout mice point to molecular basis of memory. Science 275: 32-33.

19. Stevens, C. F. 1996. Spatial learning and memory: The beginning of a dream. Cell 87: 1147-1148.

20. Crepel V, Hammond C, Krnjevic K, Chinestra P, Ben-Ari Y (1993) Anoxia-induced LTP of isolated NMDA receptor-mediated synaptic responses. J Neurophysiol 69: 1774-1778

21. Calabresi P, Centonze D, Pisani A, Cupini L, Bernardi G (2003) Synaptic plasticity in the ischaemic brain. Lancet Neurol 2: 622629

22. Jolkkonen J, Gallagher NP, Zilles K and Sivenius J. Behavioral deficits and recovery following transient focal cerebral ischemia in rats: glutamatergic and GABAergic receptor densities. Behavioural Brain Research 138 (2003) 187/200

23. Barbelivien A, Jolkkonen J, Rutkauskaite E, Sirvio“ J, Sivenius J. Differentially altered cerebral metabolism in ischemic rats by a 2 - adrenoceptor blockade and its relation to improved limbplacing reactions. Neuropharmacology 2002; 42: 117/ 26.

24. Nakazawa T, Watabe AM, Tezuka T, Yoshida Y, Yokoyama $K$, Umemori H, Inoue A, Okabe S, Manabe T, Yamamoto T (2003) p250GAP, a novel brain-enriched GTPase-activating protein for Rho family GTPases, is involved in the N-methyl- D -aspartate receptor signaling. Mol Biol Cell 14: 2921-2934

25. Noerenberg W, Hofmann F, Illes P, Aktories K, Meyer DK (1999) Rundown of somatodendritic N-methyl- D -aspartate (NMDA) receptor channels in rat hippocampal neurones: evidence for a role of the small GTPase RhoA. Br J Pharmacol 127: 1060-1063

26. Zhou M, Baudry M (2006) Developmental changes in NMDA neurotoxicity reflect developmental changes in subunit composition of NMDA receptors. J Neurosci 26(11): 2956-2963

27. Miller FD, Kaplan DR. Neurotrophin signalling pathways regulating neuronal apoptosis. Cell Mol Life Sci. 2001; 58: $1045-$ 1053.
28. Ploughman M, Windle $\mathrm{V}$, MacLellan $\mathrm{CL}$, White $\mathrm{N}$, Doré JJ and Corbett D. Brain-Derived Neurotrophic Factor Contributes to Recovery of Skilled Reaching After Focal Ischemia in Rats. Stroke. 2009; 40: 1490-1495.

29. Cowansage KK, LeDoux JE, Monfils MH. Brain-derived neurotrophic factor: a dynamic gatekeeper of neural plasticity. Current molecular pharmacology. 2010; 3(1): 12-29.

30. Tanaka J, Horiike Y, Matsuzaki M, Miyazaki T, Ellis-Davies GC, Kasai H. Protein synthesis and neurotrophin-dependent structural plasticity of single dendritic spines. Science. 2008; 319(5870): 1683-7.

31. Figurov, A., L. D. Pozzo-Miller, P. Olafsson, T. Wang, and B. Lu. 1996. Regulation of synaptic responses to high-frequency stimulation and LTP by neurotrophins in the hippocampus. Nature 381: 706-709.

32. Levine, E. S., C. F. Dreyfus, I. B. Black, and M. R. Plumer. 1995. Brain-derived neurotrophic factor rapidly enhances synaptic transmission in hippocampal neurons via postsynaptic tyrosine kinase receptors. Proc. Natl. Acad. Sci. USA 92: 8074-8077.

33. Zhang $\mathrm{H}$. et al. Bone marrow stromal cells transplantation impact spatial learning and memory and the expression of BDNF and P75NTR in rats with chronic cerebral ischemia. Life Science Journal 2012; 9(4)

34. Kiprianova I, Sandkühler J, Schwab S, Hoyer S and Spranger M. Brain-Derived Neurotrophic Factor Improves Long-Term Potentiation and Cognitive Functions after Transient Forebrain Ischemia in the Rat. Experimental Neurology 159, 511-519 (1999)

35. Kleim JA, Jones TA, Schallert T. Motor enrichment and the induction of plasticity before or after brain injury. Neurochem Res. 2003;28: 1757-1769.

36. Muller HD, Hanumanthiah KM, Diederich K, Schwab S, Schabitz WR, Sommer C. Brain-derived neurotrophic factor but not forced arm use improves long-term outcome after photothrombotic stroke and transiently upregulates binding densities of excitatory glutamate receptors in the rat brain. Stroke. 2008; 39: 10121021.

37. Monfils MH, Plautz EJ, Kleim JA. In search of the motor engram: Motor map plasticity as a mechanism for encoding motor experience. Neuroscientist. 2005; 11: 471-483.

38. Biernaskie J, Corbett D. Enriched rehabilitative training promotes improved forelimb motor function and enhanced dendritic growth after focal ischemic injury. J Neurosci. 2001; 21: 52725280 .

39. Choi, D. W. 1995. Calcium: still center-stage in hypoxic ischemic neuronal death. Trends Neurosci 18: 58-60.

40. List J. et al. Enhanced Rapid-Onset Cortical Plasticity in CADASIL as a Possible Mechanism of Preserved Cognition. Cerebral Cortex December 2011; 21: 2774-2787. 
41. Hwang I.K. et al. The immunoreactivity and activity of adenylate cyclase type I are changed in the hippocampal CA1 region after transient forebrain ischemia in gerbils. Journal of the Neurological Sciences 240 (2006) 93-98.

42. Xia ZC, Refsdal CD, Merchant KM, Dorsa DM, Storm DR. Distribution of mRNA for the calmodulin-sensitive adenylate cyclase in rat brain: expression in areas associated with learning and memory. Neuron 1991; 6: 431-43.

43. McClung, C.A., Ulery, P.G., Perrotti, L.I., Zachariou, V., Berton, O., Nestler, E.J., 2004. Delta FosB: a molecular switch for longterm adaptation in the brain. Brain Res. Mol. Brain Res. 132 (2), 146-154.

44. Allred R.P. and Jones T.A. Maladaptive effects of learning with the less-affected forelimb after focal cortical infarcts in rats. Experimental Neurology 210 (2008) 172-181. 40

45. Mattson MP, Lee RE, Adams ME, Guthrie PB, Kater SB (1988) Interactions between entorhinal axons and target hippocampal neurons: a role for glutamate in the development of hippocampal circuitry. Neuron 1: 865-876.

46. Nuijtinck RR, Baker RE, Ter Gast E, Struik ML, Mud MT (1997) Glutamate dependent dendritic outgrowth in developing neuronal networks of rat hippocampal cells in vitro. Int J Dev Neurosci 15: 55-60.

47.Lee LJ, Lo FS, Erzurumlu RS (2005) NMDA receptor-dependent regulation of axonal and dendritic branching. J Neurosci 25: 2304-2311.

48. Ai J. and Baker A. Long-term potentiation of evoked presynaptic response at CA3-CA1 synapses by transient oxygen-glucose deprivation in rat brain slices. Exp Brain Res (2006) 169: 126-129

49. Volk L, Kim CH, Takamiya K, Yu Y, Huganir RL. Developmental regulation of protein interacting with $C$ kinase 1 (PICK1) function in hippocampal synaptic plasticity and learning. Proc Natl Acad Sci USA 2010; 107: 21784.

50. Lin DT, Huganir RL. PICK1 and phosphorylation of the glutamate receptor 2 (GluR2) AMPA receptor subunit regulates GluR2 recycling after NMDA receptor-induced internalization. J Neurosci 2007; 27: 13903

51. Clem RL, Anggono V, Huganir RL. PICK1 regulates incorporation of calcium-permeable AMPA receptors during cortical synaptic strengthening. J Neurosci 2010;30:6360.

52. Hsu J.E. and Jones T.A. Contralesional neural plasticity and functional changes in the less-affected forelimb after large and small cortical infarcts in rats. Experimental Neurology 201 (2006) $479-494$

53. Schallert, T., 2006. Behavioral tests for preclinical intervention assessment. Neuro. Rx. 3 (4), 447-504.

54. Taub, E., Uswatte, G., Elbert, T., 2002. New treatments in neurorehabilitation founded on basic research. Nat. Rev., Neurosci. 3, 228-236.

55. Ward, N.S., Cohen, L.G., 2004. Mechanisms underlying recovery of motor function after stroke. Arch. Neurol. 61, 1844-1888.
56. Sun H.-S. et al. Suppression of hippocampal TRPM7 protein prevents delayed neuronal death in brain ischemia. Nature Neuroscience. 2009. Vol 12; Num 10; 1300-1307.

57.Li S, He Z, Guo L, Huang L, Wang J and He W. Behavioral alterations associated with a down regulation of HCN1 mRNA in hippocampal cornus ammon 1 region and neocortex after chronic incomplete global cerebral ischemia in rats. Neuroscience 165 (2010) 654-661

58. Costa C. et al. A critical role of NO/cGMP/PKG dependent pathway in hippocampal post-ischemic LTP: Modulation by zonisamide. Neurobiology of Disease 44 (2011) 185-191.

59. Briones T L, Suh E, Jozsa L and Woods J. Behaviorally induced synaptogenesis and dendritic growth in the hippocampal region following transient global cerebral ischemia are accompanied by improvement in spatial learning. Experimental Neurology 198 (2006) 530-538.

60. Tang Q. et al. Willed-movement training reduces motor deficits and induces a PICK1-dependent LTD in rats subjected to focal cerebral ischemia. Behavioural Brain Research 256 (2013) 481487.

61. Giuliani, D., Leone, S., Mioni, C., Bazzani, C., Zaffe, D., Botticelli, A.R., Altavilla, D., Galantucci, M., Minutoli, L., Bitto, A., Squadrito, F., Guarini, S., 2006a. Broad therapeutic treatment window of the [Nle4, D -Phe7]-melanocyte-stimulating hormone for longlasting protection against ischemic stroke, in Mongolian gerbils. Eur. J. Pharmacol. 538, 48-56.

62. Giuliani, D., Mioni, C., Altavilla, D., Leone, S., Bazzani, C., Minutoli, L., Bitto, A., Cainazzo, M., Marini, H., Zaffe, D., Botticelli, A.R., Pizzala, R., Savio, M., Necchi, D., Schiöth, H.B., Bertolini, A., Squadrito, F., Guarini, S., 2006b. Both early and delayed treatment with melanocortin 4 receptor-stimulating melanocortins produces neuroprotection in cerebral ischemia. Endocrinology 147, 126-1135.

63. Giuliani, D., Ottani, A., Mioni, C., Bazzani, C., Galantucci, M., Minutoli, L., Bitto, A., Zaffe, D., Botticelli, A.R., Squadrito, F., Guarini, S., 2007. Neuroprotection in focal cerebral ischemia owing to delayed treatment with melanocortins. Eur. J. Pharmacol. 570, 57-65.

64. Ottani, A., Giuliani, D., Mioni, C., Galantucci, M., Minutoli, L., Bitto, A., Altavilla, D., Zaffe, D., Botticelli, A.R., Squadrito, F., Guarini, S., 2009. Vagus nerve mediates the protective effects of melanocortins against cerebral and systemic damage after ischemic stroke. J. Cereb. Blood Flow Metab. 29, 512-523.

65. Giuliani, D., Ottani, A., Minutoli, L., Di Stefano, V., Galantucci, M., Bitto, A., Zaffe, D., Altavilla, D., Botticelli, A.R., Squadrito, F., Guarini, S., 2009. Functional recovery after delayed treatment of ischemic stroke with melanocortins is associated with overexpression of the activity-dependent gene Zif268. Brain Behav. Immun. 23, 844-850. 
66. Cole, A.J., Saffen, D.W., Baraban, J.M., Worley, P.F., 1989. Rapid increase of an immediate early gene messenger RNA in hippocampal neurons by synaptic NMDA receptor activation. Nature 340, 474-476.

67.Guzowski, J.F., Setlow, B., Wagner, E.K., McGaugh, J.L., 2001. Experience-dependent gene expression in the rat hippocampus after spatial learning: a comparison of the immediate-early genes Arc, c-fos, and Zif268. J. Neurosci. 21, 5089-5098.

68. Jessberger, S., Kempermann, G., 2003. Adult-born hippocampal neurons mature into activity-dependent responsiveness. Eur. J. Neurosci. 18, 2707-2712.

69. Tashiro, A., Makino, H., Gage, F.H., 2007. Experience-specific functional modification of the dentate gyrus through adult neurogenesis: a critical period during an immature stage. J. Neurosci. 27, 3252-3259.

70. Spaccapelo L. et al. Melanocortin MC 4 receptor agonists counteract late inflammatory and apoptotic responses and improve neuronal functionality after cerebral ischemia. European Journal of Pharmacology 670 (2011) 479-486.

71. Santos Da Silva, J., Schubert, V., Dotti, C.G., 2004. RhoA, Rac1, and cdc42 intracellular distribution shift during hippocampal neuron development. Mol Cell Neurosci 27, 1-7.

72. Van Aelst, L., Cline, H.T., 2004. Rho GTPases and activitydependent dendrite development. Curr Opin Neurobiol 14, 297304.

73. Huang L, He Z, Guo L and Wang H. Improvement of Cognitive Deficit and Neuronal Damage in Rats with Chronic Cerebral Ischemia via Relative Long-term Inhibition of Rho-kinase. Cell Mol Neurobiol (2008) 28: 757-768.

74. Gutiérrez-Vargas J, Castro-Álvarez JF, Velásquez-Carvajal David, Montañez-Velásquez MN, Céspedes-Rubio A and CardonaGómez GP. Rac1 activity changes are associated with neuronal pathology and spatial memory long-term recovery after global cerebral ischemia. Neurochemistry International 57 (2010) 762773.

75. He Z, Liao Y, Zheng M, Zeng F-D and Guo L-J. Piracetam Improves Cognitive Deficits Caused by Chronic Cerebral Hypoperfusion in Rats. Cell Mol Neurobiol (2008) 28: 613-627.

76. Rothstein, J.D., Patel, S., Regan, M.R., Haenggeli, C., Huang, Y.H., Bergles, D.E., Jin, L., Hoberg, M.D., Vidensky, S., Chung, D.S., Toan, S.V., Bruijn, L.I., Su, Z.Z., Gupta, P. \& Fisher, P.B. (2005). beta-Lactam antibiotics offer neuroprotection by increasing glutamate transporter expression. Nature, 433(7021), 73-77.

77. Chu, K., Lee, S.T., Sinn, D.I., Ko, S.Y., Kim, E.H., Kim, J.M., Kim, S.J., Park, D.K., Jung, K.H., Song, E.C., Lee, S.K., Kim, M. \& Roh, J.K. (2007). Pharmacological Induction of Ischemic Tolerance by Glutamate Transporter-1 (EAAT2) Upregulation. Stroke, 38(1), 177-182.

78. Han JS (1999) Principal of neuroscience. Press of Peking medical university Peking
79. GÁSPÁROVÁ Z Z, ŠNIRC V and ŠTOLC S. The new pyridoindole antioxidant SMe1EC2 and its intervention in hypoxia/ hypoglycemia-induced impairment of long-term potentiation in rat hippocampus. Interdisc Toxicol. 2011; Vol. 4(1): 56-61.

80. Yao $Y$, Han DD, Zhang $T$ and Yang Z. Quercetin Improves Cognitive Defi cits in Rats with Chronic Cerebral Ischemia and Inhibits Voltage-dependent Sodium Channels in Hippocampal CA1 Pyramidal Neurons. Phytother. Res. 24: 136-140 (2010).

81. He Z, Huang L, Wu Y, Wang J, Wang H and Guo L. DDPH: Improving cognitive deficits beyond its a 1 -adrenoceptor antagonism in chronic cerebral hypoperfused rats. European Journal of Pharmacology 588 (2008) 178-188.

82. Pu F, Mishima K, Irie K et al. 2007. Neuroprotective effects of quercetin and rutin on spatial memory impairment in an 8-arm radial maze task and neuronal death induced by repeated cerebral ischemia in rats. J Pharmacol Sci 104: 329-334.

83. Mori K, Togashi H, Ken-ichi, Hueno, Matsumoto M and Yoshioka M. Aminoguanidine prevented the impairment of learning behavior and hippocampal long-term potentiation following transient cerebral ischemia. Behavioural Brain Research 120 (2001) 159-168.

84. YOSHIOKA M. et al. Effects of ibudilast on hippocampal longterm potentiation and passive avoidance responses in rats with transient cerebral ischemia. Pharmacological Research, Vol. 45, No. 4, 2002, 305-311.

85. Arancio, O., Kiebler, M., Lee, C.J., Lev-Ram, V., Tsien, R.Y., Kandel, E.R., Hawkins, R.D., 1996. Nitric oxide acts directly in the presynaptic neuron to produce long-term potentiation in cultured hippocampal neurons. Cell 87, 1025-1035.

86. Bohme, G.A., Bon, C., Stutzmann, J.M., Doble, A., Blanchard, J.C., 1991. Possible involvement of nitric oxide in long-term potentiation. Eur. J. Pharmacol. 199, 379-381.

87. Noda, Y., Mori, A., Packer, L., 1999. Zonisamide inhibits nitric oxide synthase activity induced by $\mathrm{N}$-methyl-D-aspartate and buthionine sulfoximine in the rat hippocampus. Res. Commun. Mol. Pathol. Pharmacol. 105, 23-33.

88. Li Z, Wang Y, Xie Y, Yang Z and Zhang T. Protective Effects of Exogenous Hydrogen Sulfide on Neurons of Hippocampus in a Rat Model of Brain Ischemia. Neurochem Res (2011) 36: 18401849.

89. Stroemer R.P. et al, Kent TA and Hulsebosch CE. Enhanced Neocortical Neural Sprouting, Synaptogenesis, and Behavioral Recovery With D-Amphetamine Therapy After Neocortical Infarction in Rats. Stroke. 1998; 29: 2381-2395

90. Bliss TVP and Collingridge GL (1993). A synaptic model of memory; long-term potentiation in the hippocampus. Nature 361, 31-39.

91. Nolan MF, Malleret G, Dudman JT, Buhl DL, Santoro B, Gibbs E, Vronskaya S, Buzsáki G, Siegelbaum SA, Kandel ER, Morozov A (2004) A behavioral role for dendritic integration: HCN1 channels constrain spatial memory and plasticity at inputs to distal dendrites of CA1 pyramidal neurons. Cell 119: 719-732. 
92. Li J. et al. Synaptic plasticity in hippocampal CA1 neurons and learning behavior in transient ischemia-loaded gerbils. Biomedical Research 34 (2) 75-85, 2013.

93. Guarini, S., Bazzani, C., Bertolini, A., 1997. Resuscitating effect of melanocortin peptides after prolonged respiratory arrest. $\mathrm{Br}$. J. Pharmacol. 121, 1454-1460.

94. Guarini, S., Cainazzo, M.M., Giuliani, D., Mioni, C., Altavilla, D., Marini, H., Bigiani, A., Ghiaroni, V., Passaniti, M., Leone, S., Bazzani, C., Caputi, A.P., Squadrito, F., Bertolini, A., 2004. Adrenocorticotropin reverses hemorrhagic shock in anesthetized rats through the rapid activation of a vagal anti-inflammatory pathway. Cardiovasc. Res. 63, 357-365.

95. Guarini, S., Tagliavini, S., Bazzani, C., Ferrari, W., Bertolini, A., 1990. Early treatment with ACTH-(1-24) in a rat model of hemorrhagic shock prolongs survival and extends the time-limit for blood reinfusion to be effective. Crit. Care Med. 18, 862865.

96. Noera, G., Lamarra, M., Guarini, S., Bertolini, A., 2001. Survival rate after early treatment for acute type-A aortic dissection with ACTH-(1-24). Lancet 358, 469-470.

97. Mioni, C., Bazzani, C., Giuliani, D., Altavilla, D., Leone, S., Ferrari, A., Minutoli, L., Bitto, A., Marini, H., Zaffe, D., Botticelli, A.R., Iannone, A., Tomasi, A., Bigiani, A., Bertolini, A., Squadrito, F., Guarini, S., 2005. Activation of an efferent cholinergic pathway produces strong protection against myocardial ischemia/ reperfusion injury in rats. Crit. Care Med. 33, 2621-2628.

98. Digicaylioglu M, Lipton SA: Erythropoietin-mediated neuroprotection involves cross-talk between Jak2 and NFkappaB signalling cascades. Nature 2001, 412:641-647.

99. Siren $A L$, Fratelli $M$, Brines $M$, Goemans C, Casagrande $S$, Lewczuk $P$, et al: Erythropoietin prevents neuronal apoptosis after cerebral ischemia and metabolic stress. Proc Natl Acad Sci USA 2001, 98: 4044-4049.

100. Ruscher K, Freyer D, Karsch M, Isaev N, Megow D, Sawitzki B, et al: Erythropoietin is a paracrine mediator of ischemic tolerance in the brain: evidence from an in vitro model. J Neurosci 2002, 22: 10291-10301.

101. Byts N, Siren AL: Erythropoietin: a multimodal neuroprotective agent. Exp Transl Stroke Med 2009, 1:4

102. Undén J, Sjölund C, Länsberg J-K, Wieloch T, Ruscher $K$ and Romner B. Post-ischemic continuous infusion of erythropoeitin enhances recovery of lost memory function after global cerebral ischemia in the rat. BMC Neuroscience 2013, 14:27.

103. Michel L. Samson, Kosuke Kajitani and George S. Robertson. Nitric-Oxide Synthase Mediates the Ability of Darbepoetin Alfa to Attenuate Pre-Existing Spatial Working Memory Deficits in Rats Subjected to Transient Global Ischemia. The journal of pharmacology and experimental therapeutics. Vol. 333, No. 2, 2010, 437-444.

104. Zhao Y, Wang J, Liu C, Jiang C, Zhao C and Zhu Z. Progesterone Influences Postischemic Synaptogenesis in the CA1 Region of the Hippocampus in Rats. SYNAPSE 65: 880-891 (2011).
105. Manitt, C., Nikolakopoulou, A.M., Almario, D.R., Nguyen, S.A., Cohen-Cory, S., 2009. Netrin participates in the development of retinotectal synaptic connectivity by modulating axon arborization and synapse formation in the developing brain. J. Neurosci. 29, 11065-11077.

106. Jönsson-Berling, B.M., Ohlsson, K. and Rosengren, M. Radioimmunological quantitation of the urinary trypsin inhibitor in normal blood and urine. Biol. Chem. Hoppe-Seyler 370: 11571161, 1989

107. Okuhama, Y., Shiraishi, M., Miyaguni, T., Higa, T., Tomori, H., Hiroyasu, S. and Muto, Y. Evidence of neutrophil involvement in the protective effects of urinary trypsin inhibitor against ischemia reperfusion in vitro. Transplant Proc. 30: 3723-3725, 1998.

108. Panegyres, P.K. (2001) The functions of the amyloid precursor protein gene. Rev. Neurosci., 12, 1-39.

109. Clarke J, Thornell A, Corbett D, Soininen $H$, Hiltunen $M$ and Jolkkonen J. Overexpression of APP provides neuroprotection in the absence of functional benefit following middle cerebral artery occlusion in rats. European Journal of Neuroscience, Vol. 26, pp. 1845-1852, 2007.

110. Waterland JC. The supportive framework for willed movement. Am J Phys Med 1967; 46: 266.

111. Tang Q, Yang Q, Hu Z, Liu B, Shuai J, Wang G, et al. The effects of willed movement therapy on AMPA receptor properties for adult rat following focal cerebral ischemia. Behav Brain Res 2007; 181: 254.

112. Maldonado MA, Allred RP, Felthauser EL, Jones TA. Motor skill training, but not voluntary exercise, improves skilled reaching after unilateral ischemic lesions of the sensorimotor cortex in rats. Neurorehabil Neural Repair 2008; 22: 250.

113. Griesbach GS, Hovda DA, Molteni R, Wu A, Gómez-Pinilla F. Voluntary exercise following traumatic brain injury: brainderived neurotrophic factor upregulation and recovery of function. Neuroscience. 2004; 125(1): 129-139.

114. Adkins DL, Boychuk A, Remple MS, Kleim JA. Motor training induces experience-specific patterns of plasticity across motor cortex and spinal cord. J Appl Physiol. 2006; 101(6): 1776-1782.

115. Black JE, Isaacs KR, Anderson BJ, Alcantara AA, Greenough WT. Learning causes synaptogenesis, whereas motor activity causes angiogenesis, in cerebellar cortex of adult rats. Proc Natl Acad Sci U S A. 1990; 87(14): 5568-5572.

116. Monfils $\mathrm{MH}$, Plautz EJ, Kleim JA. In search of the motor engram: motor map plasticity as a mechanism for encoding motor experience. Neuroscientist. 2005; 11(5): 471-483.

117. Kleim, J.A., Barbay, S., Nudo, R.J., 1998. Functional reorganization of the rat motor cortex following motor skill learning. J. Neurophysiol. 80, 3321-3325.

118. Kleim, J.A., Cooper, N.R., VandenBerg, P.M., 2002. Exercise induces angiogenesis but does not alter movement representations within rat motor cortex. Brain Res. 934, 1-6. 
119. Plautz, E.J., Milliken, G.W., Nudo, R.J., 2000. Effects of repetitive motor training on movement representations in adult squirrel monkeys: role of use versus learning. Neurobiol. Learn. Mem. 74, 27-55.

120. Pagnussat AS et al. Effects of skilled and unskilled training on functional recovery and brain plasticity after focal ischemia in adult rats. Brain Research 1486 (2012) 53-61.

121. Askim T, Indredavik B, Vangberg $T$ and Håberg A. Motor Network Changes Associated With Successful Motor Skill Relearning After Acute Ischemic Stroke: A Longitudinal Functional Magnetic Resonance Imaging Study. Neurorehabil Neural Repair 2009 23: 295.

122. Matthews PM, Johansen-Berg $H$, Reddy $H$. Non-invasive mapping of brain functions and brain recovery: applying lessons from cognitive neuroscience to neurorehabilitation. Restor Neurol Neurosci. 2004; 22(3-5): 245-260.

123. Mizumori SY, Garcia PA and Raja MA. Spatial - and Locomotion - Related Neural Representation in Rat Hippocampus Following Long-Term Survival From Ischemia. Behavioral Neuroscience 1995, Vol. 109, No. 6, 1081-1094.

124. Biernaskie J, Chernenko G, Corbett D. Efficacy of rehabilitative experi ence declines with time after focal ischemic brain injury. J Neurosci. 2004; 24(5): 1245-1254.

125. Dobkin B. Confounders in rehabilitation trials of task-oriented training [published correction appears in Neurorehabil Neural Repair. 2007;21(2):195]. Neurorehabil Neural Repair. 2007; 21(1): 3-13.

126. Stroke Unit Trialists' Collaboration. Organised inpatient (stroke unit) care for stroke [update in Cochrane Database Syst Rev. 2007; (4): CD000197]. Cochrane Database Syst Rev. 2002; (1): CD000197.

127. Verheyden G, Nieuwboer A, De Wit, L, et al. Time course of trunk, arm, leg, and functional recovery after ischemic stroke. Neurorehabil Neural Repair. 2008; 22(2): 173-179.

128. Krakauer JW. Motor learning: its relevance to stroke recovery and neuro-rehabilitation. Curr Opin Neurol. 2006; 19(1): 84-90.

129. Molteni R, Zheng J-Q, Ying Z, Gómez-Pinilla F, Twiss JL. Voluntary exercise increases axonal regeneration from sensory neurons. Proc Natl Acad Sci U S A. 2004; 101(22): 8473-8478.

130. Ding YH, Li J, Zhou Y, Rafols JA, Clark JC, Ding Y. Cerebral angiogenesis and expression of angiogenic factors in aging rats after exercise. Curr Neurovasc Res. 2006; 3(1): 15-23.

131. Li J, Luan X, Clark JC, Rafols JA, Ding Y. Neuroprotection against transient cerebral ischemia by exercise pre-conditioning in rats. Neurol Res. 2004;26 (4): 404-408.

132. Johansson, B.B., 1996a. Environmental influence on outcome after experiment brain infarction. Acta Neurochir., Suppl. (Wien) $66,63-67$

133. Johansson, B.B., 2004. Functional and cellular effects of environmental enrichment after experimental brain infarcts. Restor. Neurol. Neurosci. 22, 163-174.
134. Johansson, B.B., Ohlsson, A.L., 1996. Environment, social interaction, and physical activity as determinants of functional outcome after cerebral infarction in the rat. Exp. Neurol. 139, 322-327.

135. Ohlsson, A.L., Johansson, B.B., 1995. Environment influences functional outcome of cerebral infarction in rats. Stroke 26, 644-649.

136. Green, E.J., Greenough, W.T., Schlumpf, B.E., 1983. Ejects of complex or isolated environments on cortical dendrites of middle-aged rats. Brain Res. 264, 233-240.

137. Greenough, W.T., Hwang, H.M., Gorman, C., 1985. Evidence for active synapse formation or altered postsynaptic metabolism in visual cortex of rats reared in complex environments. Proc. Natl. Acad. Sci. USA 82, 4549-4552.

138. Johansson, B.B., 1996. Functional outcome in rats transferred to an enriched environment 15 days after focal brain ischemia. Stroke 27, 324-326.

139. Moser, M.-B., Trommald, M., Andersen, P., 1994. An increase in dendritic spine density on hippocampal CA1 pyramidal cells following spatial learning in adult rats suggests the formation of new synapses. Proc. Natl. Acad. Sci. USA 91, 12673-12675.

140. Moser, M.-B., Trommald, M., Egeland, T., Andersen, P., 1997. Spatial training in a complex environment and isolation alter the spine distribution differently in rat CA1 pyramidal cells. J. Comp. Neurol. 380, 373-381.

141. Risedal, A., Zeng, J., Johansson, B.B., 1999. Early training may exacerbate brain damage after focal brain ischemia in the rat. J. Cereb. Blood Flow Metab. 19, 997-1003.

142. Young, D., Lawlor, P.A., Leone, P., Dragunow, M., During, M.J., 1999. Environmental enrichment inhibits spontaneous apoptosis, prevents seizures and is neuroprotective. Nat. Med. 5, 448-453.

143. Rampon, C., Tang, Y.-P., Goodhouse, J., Shimizu, E., Kyin, M., Tsien, J.Z., 2000b. Enrichment induces structural changes and recovery from nonspatial memory dęccits in CA1 NMDAR1knockout mice. Nat. Neurosci. 3, 238-244.

144. Zhu $\mathrm{H}$ et al. An enriched environment reverses the synaptic plasticity deficit induced by chronic cerebral hypoperfusion. Neuroscience Letters 502 (2011) 71-75.

145. Dahlqvist $P$, Rönnbäck A, Bergström S-A, Söderström I and Olsson T. Environmental enrichment reverses learning impairment in the Morris water maze after focal cerebral ischemia in rats. European Journal of Neuroscience, vol. 19, pp. 2288-2298, 2004

146.J. Nithianantharajah, A.J. Hannan, Enriched environments, experience-dependent plasticity and disorders of the nervous system, Nat. Rev. Neurosci. 7 (2006) 697-709.

147. V. Paban, M. Jaffard, C. Chambon, M. Malafosse, B. AlescioLautier, Time course of behavioral changes following basal forebrain cholinergic damage in rats: environmental enrichment as a therapeutic intervention, Neuroscience 132 (2005) 13-32. 
148. FARRELL R, EVANS $S$ and CORBETT D. Environmental enrichment enhances recovery of function but exacerbates ischemic cell death. Neuroscience Vol. 107, No. 4, pp. 585-592, 2001.

149. H. Sun, J. Zhang, L. Zhang, H. Liu, H. Zhu, Y. Yang, Environmental enrichment influences BDNF and NR1 levels in the hippocampus and restores cognitive impairment in chronic cerebral hypoperfused rats, Curr. Neurovasc. Res. 7 (2010) 268280.

150. Dahlqvist, P., Ronnback, A., Risedal, A., Nergardh, R., Johansson, I.M., Seckl, J.R., Johansson, B.B., Olsson, T., 2003. Effects of postischemic environment on transcription factor and serotonin receptor expression after permanent focal cortical ischemia in rats. Neuroscience 119, 643-652.

151.Zhao, L.R., Risedal, A., Wojcik, A., Hejzlar, J., Johansson, B.B., Kokaia, Z., 2001. Enriched environment influences brain-derived neurotrophic factor levels in rat forebrain after focal stroke. Neurosci. Lett. 305, 169-172.

152. Matsumori $Y$, Hong SM, Fan $Y$, Kayama T, Hsu C, Weinstein $P$ and Liu J. Enriched environment and spatial learning enhance hippocampal neurogenesis and salvages ischemic penumbra after focal cerebral ischemia. Neurobiology of Disease 22 (2006) 187-198.

153. Briones TL, Therrien B and Metzger B. Effects of Environment on Enhancing Functional Plasticity following Cerebral Ischemia. Biol Res Nurs 2000 1: 299.

154. Cao LJ, Wang J, Hao PP, Sun CL and Chen YG. Effects of Ulinastatin, a Urinary Trypsin Inhibitor, on Synaptic Plasticity and Spatial Memory in a Rat Model of Cerebral Ischemia/Reperfusion Injury. Chinese Journal of Physiology 54(6): 435-442, 2011

\section{Comment on this article:}

\section{(f) $B$ in $8+S$.}

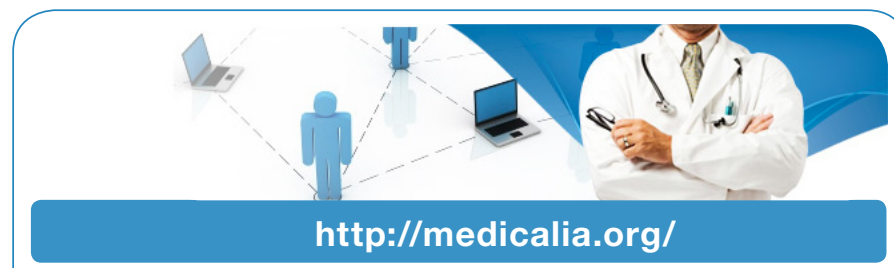

Where Doctors exchange clinical experiences, review their cases and share clinical knowledge. You can also access lots of medical publications for free. Join Now!

\section{Publish with iMedPub}

http://www.imed.pub

International Archives of Medicine is an open access journal publishing articles encompassing all aspects of medical science and clinical practice. IAM is considered a megajournal with independent sections on all areas of medicine. IAM is a really international journal with authors and board members from all around the world. The journal is widely indexed and classified Q1 in category Medicine. 